\title{
A Foreigner Who Doesn't Steal My Job: The Role of Unemployment Risk and Values in Attitudes towards Equal Opportunities
}

\author{
Marco Pecoraro \\ marco.pecoraro@unine.ch \\ and \\ Didier Ruedin \\ didier.ruedin@unine.ch
}

POST-PRINT

This is the final draft after refereeing

Published as: Pecoraro, Marco, and Didier Ruedin. 2016. “A Foreigner Who Doesn't Steal My Job: The Role of Unemployment Risk and Values in Attitudes towards Equal Opportunities.”

International Migration Review. 50(3):628-66. doi:10.1111/imre.12162

https://doi.org/10.1111/imre.12162

\begin{abstract}
Immigration has become systematically politicized and opposed by many individuals. We examine individual attitudes toward equal opportunities for foreigners and Swiss citizens, using crosssectional data from the Swiss Household Panel. Individuals with low levels of education tend to oppose foreigners, while the opposition by individuals with high levels of education increases with the risk of unemployment. Values and beliefs explain the negative attitudes of individuals with low levels of education, but not the association with the risk of unemployment for individuals with high levels of education. Clearly, both values and economic factors are important for explaining attitudes toward foreigners.
\end{abstract}




\title{
A Foreigner Who Doesn't Steal My Job: The Role of Unemployment Risk and Values in Attitudes towards Equal Opportunities
}

\begin{abstract}
Immigration has become systematically politicized and opposed by many individuals. We examine individual attitudes towards equal opportunities for foreigners and Swiss citizens, using cross-sectional data from the Swiss Household Panel. Individuals with low levels of education tend to oppose foreigners, while the opposition by individuals with high levels of education increases with the risk of unemployment. Values and beliefs explain the negative attitudes of individuals with low levels of education, but not the association with the risk of unemployment for individuals with high levels of education. Clearly, both values and economic factors are important for explaining attitudes towards foreigners.
\end{abstract}

Keywords: Immigration, attitudes towards equal opportunities, attitudes towards immigration, labour market competition, unemployment risk, values and beliefs

\section{Introduction}

Over the past three decades, immigration has become one of the most prominent topics in election campaigns, systematically politicized by parties on the right. Across Western Europe, there appears to be growing support for anti-immigrant policies and organizations associated with anti-immigrant sentiments. The most common and perhaps most basic explanation for attitudes towards foreigners revolves around the idea of economic competition. Following this approach, negative attitudes towards foreigners and immigrants are seen as a direct reaction against unwanted competition in the labour market. Despite a growing literature on the attitudes of the mainstream society towards foreigners and immigrants, the exact role of education remains poorly understood, especially given that the impact of education is unlikely to be uniform (Jenssen and Engesbak 1994). While an association between low levels of education and negative sentiments towards immigrants can be found across countries, the underlying mechanism remains poorly specified.

In this article, we assess to which extent the labour market competition hypothesis is relevant in shaping attitudes towards foreign citizens in Switzerland. We focus on Switzerland for several reasons: With more than a fifth of the population being foreign citizens, and a concentration of immigrants in both low skilled and highly skilled occupations, Switzerland offers an ideal case to study the role of education in attitudes towards immigrants. The high level of economic prosperity and low unemployment rates would lead us to expect low levels of grievances against foreigners, but Switzerland has seen the electoral success of the right-wing Swiss People's Party - a party drawing heavily on a rhetoric that depicts immigration as a negative influence on Swiss citizens (Ruedin 2013). In this rhetoric, it is taken for granted that more immigration leads to wage dumping and job displacement through increased competition in the labour market among native workers. 
There is a burgeoning literature on attitudes towards immigrants drawing on different theoretical traditions. A basic tenet is the competition - in different forms - between different groups in society, particularly different ethnic/racial groups. Sherif and Sherif (1953) and particularly Blumer's (1958) work on racial prejudice highlighted the importance of group positions and perceptions of threat (for recent theoretical developments refer to Bobo and Hutchings 1996). This perspective of competitive threat remains the staple of research on attitudes towards immigrants (for reviews refer to Ceobanu and Escandell 2010; Hainmueller and Hopkins 2014; Dancygier and Laitin 2014). Much of the literature has focused on economic threats such as the competition over jobs and salaries, but other forms of threat are recognized.

Competitive threat theory has the advantage that it allows the formulation of clear hypotheses (Coenders and Scheepers 1998). It is largely compatible with rational action approaches that regard individuals as self-interested: negative attitudes towards immigrants can be seen as a simple protection against unwanted competitors (Borjas 1999). There is empirical support for the argument that economic competition is associated with negative attitudes towards immigrants (e.g. Scheve and Slaughter 2001; Mayda 2006; Ortega and Polavieja 2012), but the argument has been refined by economists and sociologists alike. Particular attention is paid to the many noneconomic explanations for negative attitudes, including the role of (group) identities and individual-level values and beliefs (e.g. Hainmueller and Hiscox 2007; Sides and Citrin 2007; Müller and Tai 2010) and the multiple factors that influence perceptions of threat (e.g. Bobo and Hutchings 1996; Semyonov et al. 2004; Hello, Scheepers, and Sleegers 2006). These contributions highlight that the individual situation in the labour market plays a less significant role in shaping attitudes towards immigrants once values and beliefs are accounted for. In their recent review, Hainmueller and Hiscox (2014) argue strongly that the individual economic situation plays only a minor role. The economic situation is not unimportant, however, since sociotropic concerns with the economy of the country or locality are among the most potent predictors for negative attitudes towards immigrants. In this sense, the existing evidence highlights the importance of the group level underlined by Blumer (1958) many decades ago. Rather than largely dismissing the labour force channel as Hainmueller and Hiscox seem to do, Facchini et al. (2013) take a more conciliatory approach, arguing that economic and non-economic factors play a complementary role in explaining attitudes towards immigrants.

Previous literature reveals three significant shortcomings. First, existing studies assume that the immigrants in a receiving country are either predominantly unskilled or predominantly skilled. For most countries, this means that the immigrant population is regarded as lower skilled than the native population. Accordingly, only low skilled individuals of the native population are exposed to competition from immigration. By so doing, however, these studies ignore the fact that the skill distribution of immigration tends to be somewhat bimodal, with peaks at both the high skill and low skill ends of the distribution (e.g. Borjas, Friedman, and Katz 1997; Kahn 2004; Felbermayr and Kohler 2007). This means that highly skilled workers are also exposed to competition from immigrants, with corresponding implications on attitudes towards immigration. Second, as shown by Malhotra et al. (2013) most studies equate education with skills. Ortega and Polavieja (2012), however, stress that defining skills solely in terms of educational attainment constitutes a very narrow definition of the human capital resources that characterize native-foreigner competition in the labour market. It follows that these studies provide an incomplete 
test for the labour market competition hypothesis. Third, earlier research that investigated the labour market determinants of attitudes towards immigration relied on dependent variables measuring respondents' desired levels of immigration in their home country. Such subjective measures do not capture the attitudes of natives towards competition from foreign workers directly; they may reflect a wide range of reasons as to why natives have negative attitudes towards immigrants.

For a better understanding of the role of education, we assess the relevance of the labour market competition hypothesis in explaining individual attitudes towards equal opportunities for foreign and Swiss citizens. To fulfil this objective, we examine to what extent education and labour market skills correspond, rather than making the assumption that they largely do. We control for non-economic factors such as opinions on Swiss tradition and trust in organisations for the defence of human rights to further establish if attitudinal effects of education are independent of values and beliefs. These variables tend to correlate with levels of education, and may indeed reflect different propensities to control prejudice (Jenssen and Engesbak 1994; Blinder, Ford, and Ivarsflaten 2013), although previous research suggests that social desirability biases cannot account for all of the effects of education (Ostapczuk, Musch, and Moshagen 2009). To check the robustness of our results, skills are defined not only in terms of educational attainment but also in terms of occupational level. In the empirical analysis, we thus improve on most existing studies in three important aspects. First, we use a measure of individual preferences for equal opportunities for foreign citizens. This attitudinal variable better captures the attitudes of natives towards competition from foreigners and is thus more relevant to study the labour market determinants of attitudes towards immigration than the variables most commonly used in the literature. For reasons of comparability, we use alternative specifications drawing on variables that capture attitudes towards immigration more generally. Second, we account for nonlinearity in educational attainment, to account for the fact that foreigners are over-represented at both the bottom and the top of the education distribution. Third, while labour market competition is commonly operationalized by education, we additionally allow for interaction between education and risk of unemployment in order to better assess exposure to competition from foreigners. This means we circumvent the assumption that only workers in low skilled occupations are exposed to economic pressure from immigrants.

Using these more sophisticated measures of exposure to market competition, we find no evidence that - once values and beliefs are accounted for - workers with low levels of education a priori have more negative attitudes towards foreigners than those with upper secondary education. This finding contrasts with most prior research. Moreover, we show that even if workers with a tertiary education robustly appear to have more positive attitudes towards foreigners than their counterparts with an upper secondary education, in their case a higher risk of unemployment is associated with more negative attitudes towards foreigners.

\section{Swiss immigration policy and labour market}

As in many Western European countries, the post-war period in Switzerland was characterized by strong economic growth and the gradual liberalization of international trade. Immigration policy served as a useful macroeconomic instrument allowing the pro-cyclical exploitation of a low skilled foreign labour force in order to meet the demands of the economy. This guest-worker immigration was characterized 
by state control and corporatist agreements, and initially both settlement and contact with the indigenous population was actively discouraged. Following pressure from the public and international organizations, as well as competition from other Western European countries offering a 'better' deal for labour migrants, this approach changed during the 1960s towards a model of integration (Skenderovic and D'Amato 2008). As elsewhere, the political debate on immigration came to be dominated by two opposing movements: one side highlighted economic growth, the other side voiced concerns of overpopulation, wage dumping, and a threat to local culture. The German concept of Überfremdung combines these concerns, with concurrent connotations of there being too many immigrants and immigrants that are 'too foreign'.

Figure 1: Newspaper adverts about the purported impact of immigration
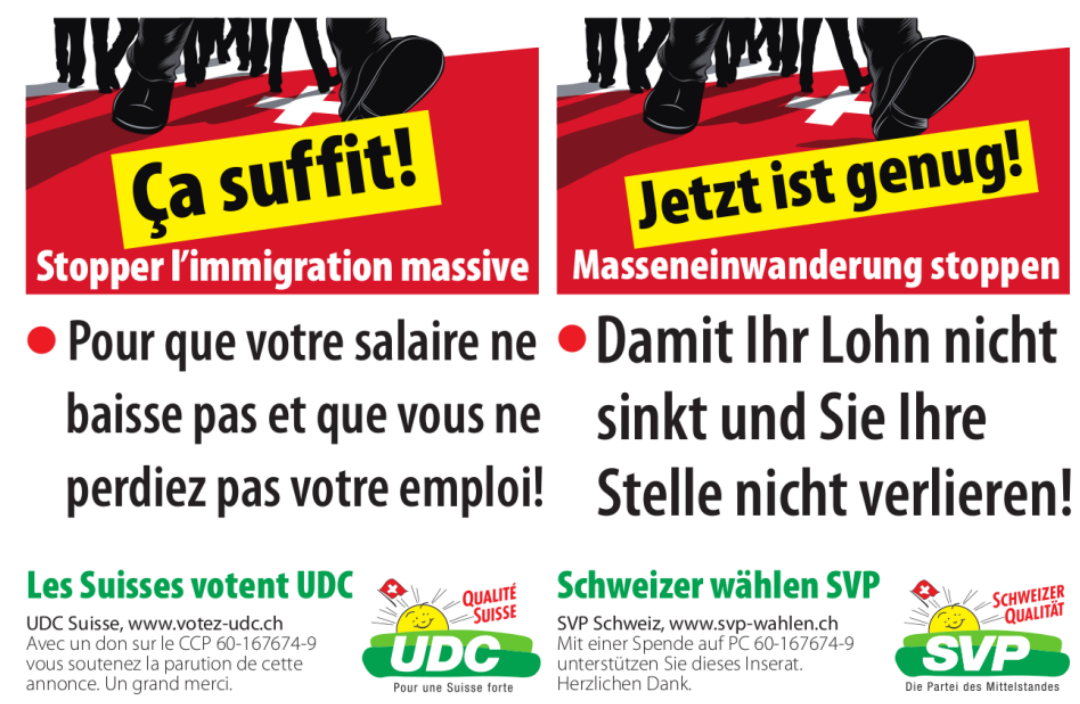

Newspaper adverts by the Swiss People's Party highlighting the purported impact of immigration on local wages and jobs, given both in French (left) and German (right): "That's enough! Stop mass immigration. To ensure that your salary does not drop and you do not lose your job!" The picture was alleged to connote an invasion by NaziGermans (Honegger 2011).

The Swiss People's party (UDC/SVP) is the main actor for mobilizing anti-immigrant sentiments in Switzerland, taking up an issue about which a large part of the population is concerned (Ruedin and D'Amato 2015). Between 1987 and 2007, the national vote share of this conservative party in parliament has increased from 11 per cent to 29 per cent. ${ }^{1}$ During the same period, there were over 20 referendums and popular initiatives on immigration-related topics. Until recently, most attempts to introduce a more restrictive immigration regime using direct democratic means were defeated at the polls, such as in 2000 when voters rejected an initiative to limit the proportion of foreign citizens to 18 per cent of the population. More recently, however, a ban on the building of new minarets was introduced in Switzerland using a popular initiative (in 2009), or a law on the automatic expulsion of foreigners guilty of crimes is awaiting enactment. The newspaper adverts in Figure 1 are recent examples of propaganda by the Swiss People's party according to which immigration induces wage dumping and job displacement. Whilst there appears to be growing support for anti-immigrant policies and organizations associated with anti-immigrant sentiments

1 The party's growth seems to have slowed, and in the most recent national election in 2011, it was unable to increase its vote share, although it remains the largest party in parliament with 27 per cent of the vote. 
in some way, it is not the case that all Swiss voters have become more hostile to immigrants.

Since the 1990s, Swiss policy increasingly favoured European immigrants and introduced restrictive policies for so-called third country nationals: immigrants from outside the European Union and the European Economic Area (EEA). With asylum seekers and family reunion, immigrant categories beyond labour immigration gained prominence, but the Swiss economy continued to struggle with a shortage of qualified labour (e.g. Huth 2004; Zimmerli et al. 2009; Schellenbauer et al. 2010). Gradually working towards free mobility with EU/EEA countries, Swiss employers were advised to fill their needs with migrants from Western European countries since 1991 and particularly since 1998. It remains possible to recruit skilled workers from outside the EU/EEA, but quotas are in place. Non-European workers are only admitted if no Swiss or European worker can be recruited to fill the vacant job. ${ }^{2}$ As a result of this focus on EU/EEA immigrants, the nature of migration flows has evolved from a mainly low educated labour force to one favouring highly qualified labour (Pecoraro 2005).

Figure 2 illustrates the result of this change in the nature of migration flows to Switzerland. It shows the distribution of educational attainment across the workingage population by different national groups (Swiss nationals, all foreigners, and foreigners settled in Switzerland within the previous five years). In the top panel, the highest fraction of workers with the lowest levels of education is found among foreign residents. On the one hand, this is a legacy of immigrant recruitment before the 1990s, where manual workers were actively sought. On the other hand, we note that recent immigrants are slightly more common in this category than Swiss citizens. This reflects the fact that the prioritizing of European immigration continues to attract immigrants with low levels of education - mostly from Italy and Portugal. The middle panel includes workers with upper secondary education, whose proportion is dominant among Swiss workers (around 60 per cent of Swiss workers fall into this category). By contrast, the proportion of tertiary-educated workers among recent foreigners clearly exceeds those among other groups in the bottom panel. Put differently, we observe a clear bipolarity in terms of educational attainment among foreigners. This concentration of immigrants at the high and low end reflects labour market shortages, and has not changed substantively in the decade under observation. The immigration policies in place seem successful in counteracting these shortages by means of immigration. Historically, this first meant a focus on low skilled labour, and since the 1990s a focus on immigration of highly skilled labour. At the same time, immigration for other reasons than work (notably family reunification or asylum) along with continued immigration from countries like Italy and Portugal ensure a supply of low skilled labour.

The increased focus on immigrants from European countries, however, did not abate concerns about immigration among the population. Immigration is consistently among the most mentioned 'most important problems' in opinion surveys (Bornschier 2010), and the continuing success of the Swiss People's Party can be understood as an indication that governmental policy does not sufficiently address concerns over immigration.

2 There are some exceptions with regard to intra-firm transfer and family reunification. Until 2004, priority was given to Swiss workers over EU-15/EFTA workers, but these restrictions have been removed. 
Figure 2: Levels of education by national group, 1999 to 2009

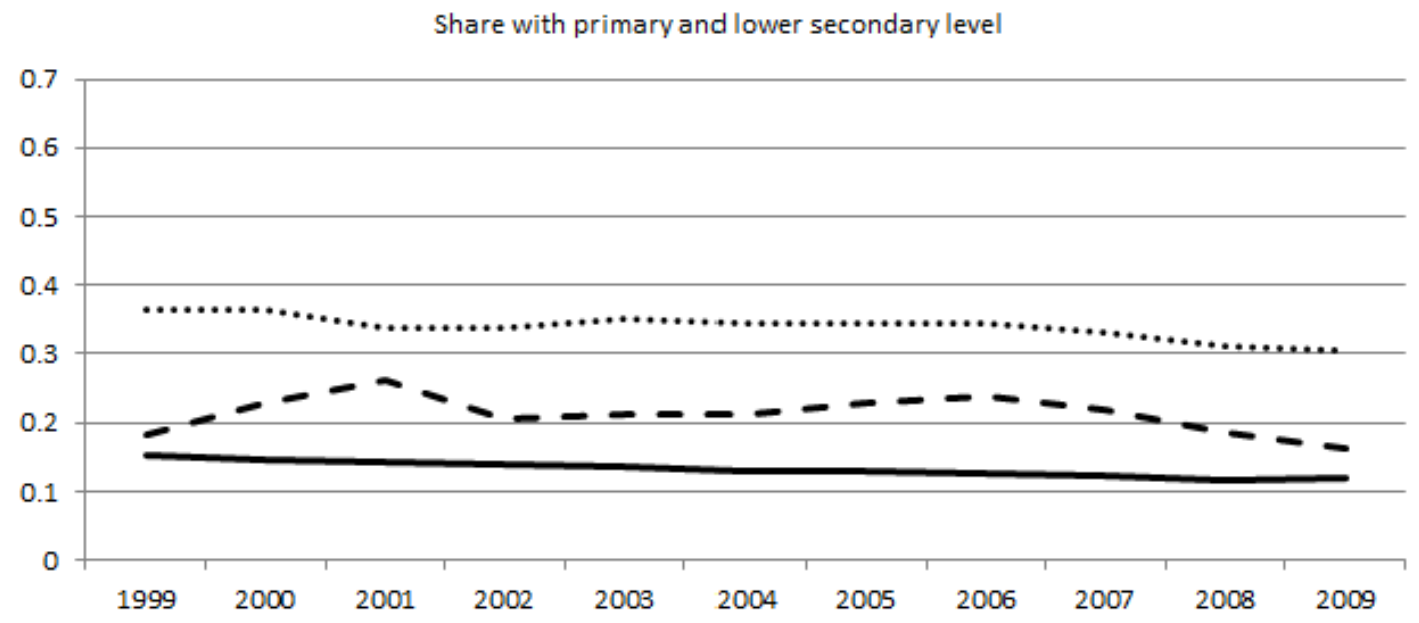

Share with upper secondary level

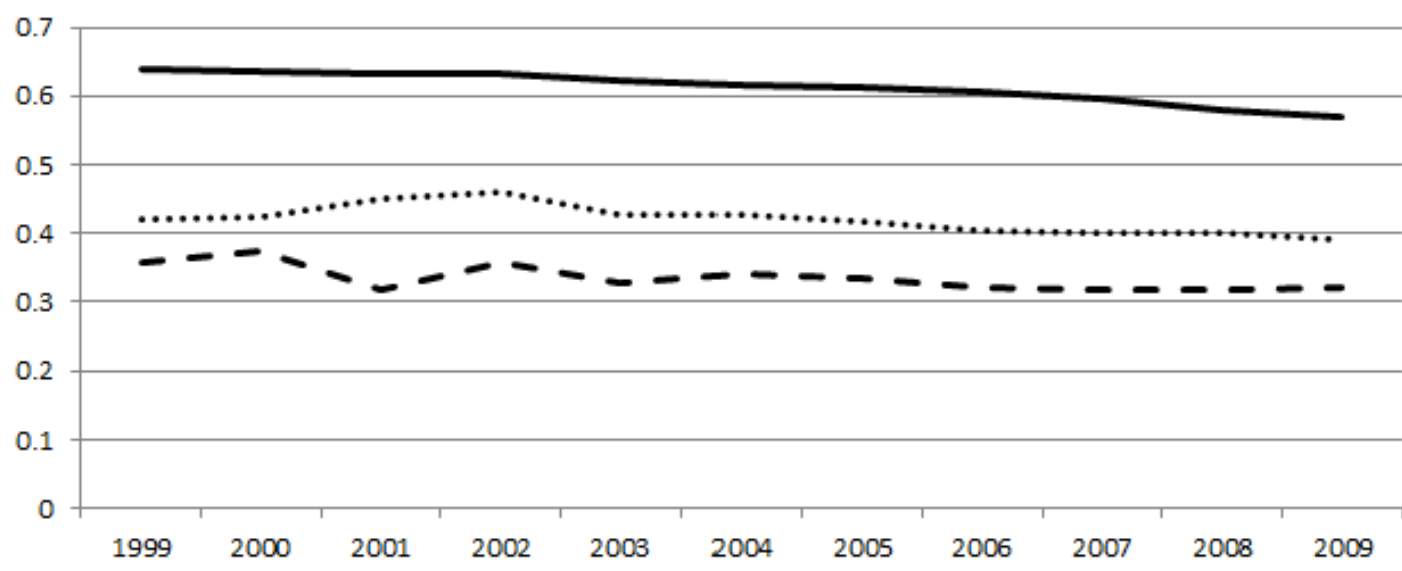

Share with tertiary level

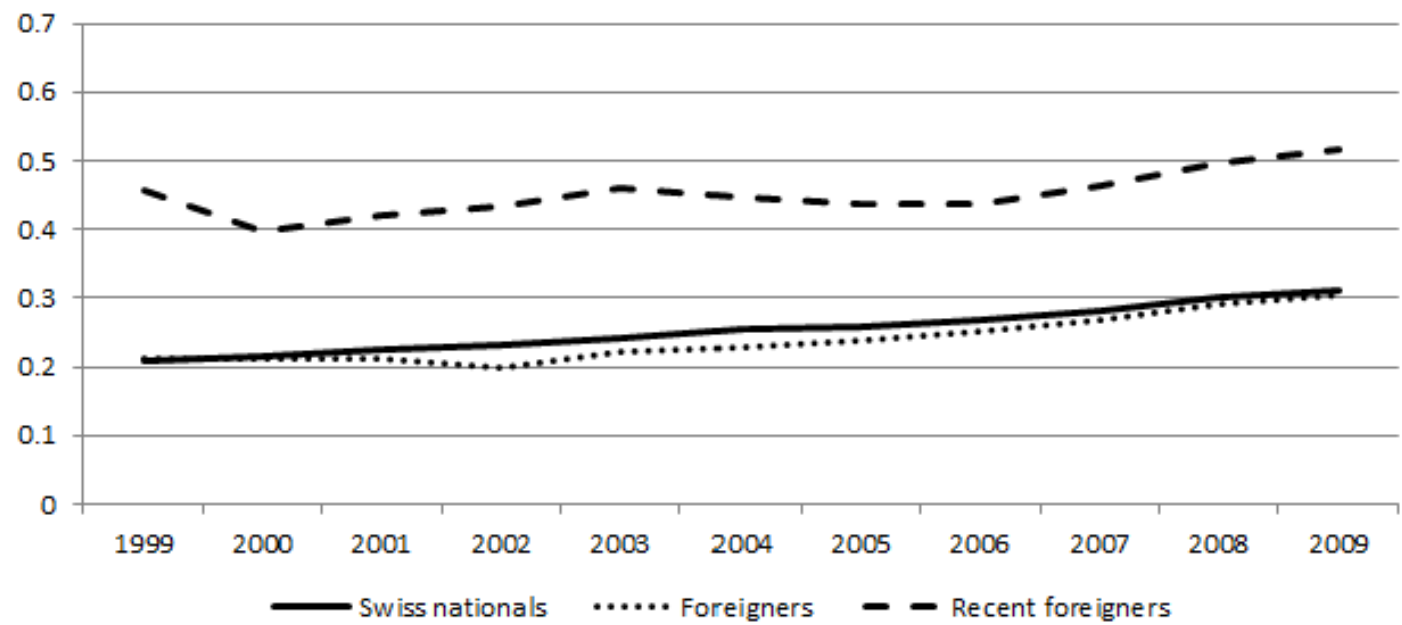

Source: Swiss Labour Force Survey 1999-2009.

Notes: Individuals aged 18-65; recent foreigners are those residing in Switzerland for less than 5 years. 


\section{Attitudes towards immigration}

Anti-immigrant sentiments may be abound in Western Europe, but not everyone shares negative feelings towards foreigners. A common explanation is that individuals who directly compete with immigrants in the labour market are more likely to oppose immigrants. The Heckscher-Ohlin approach "predicts that immigrants pressure the wages of similarly skilled natives nationwide" (Scheve and Slaughter 2001, 133). It suggests that immigration leads to lower wages for native workers whose skills are substituted by immigrants (i.e. a negative wage effect). At the same time, wages are expected to increase for native workers with complementary skills to the immigrants (i.e. a positive wage effect). It follows that if immigration increases the supply of unskilled labour relative to skilled labour, then the wages of skilled individuals are expected to rise, and the wages of unskilled individuals are expected to fall. The expectation is the opposite if immigrants are predominantly more skilled than the native workers. The implication on attitudes towards immigrants is that native workers who are more exposed to competition with immigrants are expected to have more negative attitudes, because it is in their rational self-interest to protect their wages.

Empirical research has generally supported this hypothesis, in particular that the relative skill composition of natives to immigrants in the receiving country determines the sign of correlations between education/skills and attitudes to immigration. In the US context, where it is often posited that highly skilled labour is the abundant factor and thus immigrants are less skilled than natives on average, individuals with lower levels of education are more likely to be against immigration (e.g. Espenshade and Hempstead 1996; Scheve and Slaughter 2001; Kessler 2001). Low levels of education are also a consistent factor for studies covering Europe (e.g. Dülmer and Klein 2005; Schneider 2008; Ceobanu and Escandell 2010). On the basis of cross-country survey data, Mayda (2006) and O'Rourke and Sinnott (2006) have confirmed this result. Moreover, they have shown that in countries where native workers are generally less skilled than immigrants - such as in the Philippines -, natives with lower levels of education tend to favour immigration. Using a more comprehensive measure of skills, Ortega and Polavieja (2012) have also provided support for the labour market competition hypothesis according to which individuals employed in jobs less exposed to competition with immigrants are relatively more in favour of immigration.

Only few studies reject the labour market competition hypothesis outright. For instance, Hainmueller and Hiscox (2007) have found that individuals with higher levels of education are more favourable to both skilled and unskilled immigrants. According to the authors, this result stems from the fact that education is a proxy for values and beliefs, suggesting that a different mechanism may be dominant rather than competitive threat. Sides and Citrin (2007) emphasize a social-psychological approach to attitudes towards immigration, in which the role of values and identities outweighs the influence of material concerns. Their results show that cultural and national identities matter more than economic concerns for opinion formation. Malhotra et al. (2013) use a survey experiment to underline this explanation: cultural and economic threats are different phenomena, and individuals react differently depending on which threat they perceive. Focusing on the high-technology sector in the United States, a sector that relies heavily on Indian H-1B visa holders, they find little evidence for labour market competition as driving negative attitudes towards Indian immigration. On the other hand, economic threat turns out to significantly predict opposition towards $\mathrm{H}-1 \mathrm{~B}$ immigration since (Indian) $\mathrm{H}-1 \mathrm{~B}$ visa holders are 
more directly competing with highly skilled Americans. The few studies using survey experimental settings apart, most of the aforementioned studies have tried to handle the association between education and values and beliefs by estimating specifications that account for indicators of individual values and beliefs. Despite these additional controls often being jointly significant, the relationship between education and attitudes towards foreigners remains strong. This finding suggests that the significant correlation between education and attitudes towards immigration is not primarily driven by differences in values and beliefs, reinforcing the relevance of the labour market competition hypothesis.

Few studies have examined the relationship between labour market considerations and anti-immigration attitudes in Switzerland specifically, the case under study in this article. This relative lack of studies is surprising because a number of authors have used cross-country data from the European Social Survey (ESS) or the World Value Survey (WVS), both of which include Switzerland. Few of these cross-national studies, however, have presented their results per country or only for Switzerland. Exceptions are the studies by Hainmueller and Hiscox (2007) and Green et al. (2010). While Green et al. focus on how diversity in immigration influences attitudes across Swiss municipalities - drawing on contact theory and a perspective of cultural threat -, Hainmueller and Hiscox have demonstrated that, contrary to predictions by the labour market competition hypothesis, higher levels of education mean greater support for all types of immigration (i.e. both low and highly skilled). To our knowledge, only Helbling (2011) has relied on data from a survey of Swiss citizens living in the city of Zürich. Investigating whether Swiss Germans perceive German migrants as cultural and economic threats, Helbling claims to find support for the labour market competition hypothesis, in particular: Negative attitudes towards immigrants from former Yugoslavia (who are more likely to have low levels of education) decrease with Swiss Germans' level of education but there is no significant relationship between the level of education and the Swiss Germans' dislike of German migrants.

\section{Data}

We use data from the Swiss Household Panel (SHP), a yearly panel following a random sample of households and their members in Switzerland since 1999. The SHP dataset provides useful information on various aspects of professional life as well as an indicator on whether respondents are in favour of Switzerland offering foreigners the same opportunities as those offered to Swiss citizens, or whether they favour better opportunities for Swiss citizens. Here we understand attitudes towards equal opportunities for foreigners as a case of attitudes towards foreigners more generally, and use the two terms interchangeably.

The empirical analysis is based on two waves of the panel, in 1999 and 2011, each of which is used as a cross-section. Accordingly, cross-sectional individual weights are used to produce representative estimates of the population in Switzerland. ${ }^{3}$ Hereafter, we focus on 1999 because the politicization of immigration was probably less

3 The SHP dataset includes cross-sectional weights to adjust for non-response at the individual and household level. See Graf (2009) for a detailed description of the procedures implemented for computing weights in the SHP. Using Stata's svy command, all regression analyses incorporate cross-sectional individual weights to take into account the sampling design of the SHP and obtain reliable estimates concerning the population of interest. Stata calculates robust standard errors using the 'linearization' variance estimator based on a first order Taylor series linear approximation. 
pronounced at the time than in recent years, meaning that our analyses constitute a 'least likely' case for labour force effects. ${ }^{4}$ The reported results, however, can be replicated for more recent years. As we show, estimation results for 2011 do not deviate from those presented here. These results are reported in Table 21 to Table 24 in the appendix.

In 1999, the question on equal opportunities for foreigners was asked in a more finegrained way than in subsequent years. While the variable capturing attitudes towards equal opportunities for foreigners is available in all waves, it generally uses an ordered response with three categories ('in favour of equal opportunities for foreigners' (1), 'neither of them' (2), 'in favour of better opportunities for Swiss citizens' (3)). In 1999, individuals responding 1 or 3 were also asked whether they are rather in favour or strongly in favour. This allows us to code the response as an ordered response with five categories.

Our sample consists of Swiss citizens of voting age who are active in the labour market, and we only keep respondents who reported valid information for the variables of interest (i.e. attitudes towards foreigners and risk of unemployment). In order to check whether education reflects non-labour market considerations, we additionally use subsamples of individuals not in the labour force: both the total subsample and only retired people - i.e. those aged 65 and older. Table 8 and Table 19 in the appendix give further details on the sample selection procedure for 1999 and 2011, respectively.

While the main analyses use data from the SHP survey, we also provide results drawing on the European Social Survey (ESS) and the World Value Survey (WVS). These additional analyses allow us to ascertain - rather than just assert - that the findings based on the SHP data are more generally valid. Table 20 in the appendix shows the sample selection procedure based on the ESS and WVS datasets.

\section{Methods}

To explain attitudes towards equal opportunities for foreigners, we estimate the following baseline equations broadly similar to the specification adopted in the literature analysing the determinants of attitudes towards immigration:

$$
\begin{aligned}
& y_{i}^{*}=\alpha_{S} S_{i}+\mathbf{X}_{i} \boldsymbol{\beta}+\square \varepsilon_{i} \\
& y_{i}^{*}=\alpha_{1} L_{1 \mathrm{i}}+\alpha_{3} L_{3 \mathrm{i}}+\mathbf{X}_{i} \boldsymbol{\beta}+\square \varepsilon_{i}
\end{aligned}
$$

where the dependent variable $y_{i}^{*}$ is the unobserved latent variable for attitudes towards foreigners, $\mathbf{X}_{i}$ is a vector of observed personal characteristics, including a dummy for gender, age, age squared, a binary variable for father's and mother's

4 Recall that while immigration is perhaps increasingly politicized in recent years, it has been the topic of heated debates in Switzerland at least since the 1970s with the so-called Schwarzenbach initiatives to limit the proportion of foreigners (Ruedin and D'Amato 2015). 
national origin respectively. ${ }^{5}$ Two specifications are used: Equation (1) incorporates years of schooling $S_{i}$, while in equation (2) years of schooling are replaced by levels of schooling $L_{h i}$ (with $h \in\{1,2,3\}$ ). According to the second specification, individuals with primary or lower secondary education $(h=1)$ and individuals with tertiary education $(h=3)$ are compared to those with upper secondary education $(h=2)$. Years and levels of schooling are both derived from the highest level of education achieved, consisting of 10 levels classified in an increasing hierarchical order. While Table 9 in the appendix shows how each level of education is translated into the total number of years of schooling, ${ }^{6}$ Table 10 in the appendix presents all explanatory variables included in the regression analyses, and descriptive sample statistics are shown in Table 11 in the appendix.

In order to account for the ordinal nature of the observed dependent variable $y_{i}$, we use ordered probit estimations where

$\square \varepsilon_{i} \mid$ covariates $\sim \operatorname{Normal}(0,1)$.

The continuous latent variable $y_{i}^{*}$ can be thought of as the propensity to exhibit positive attitudes towards foreigners. The observed response categories are tied to the latent variable as follows:

$$
y_{i}=\left\{\begin{array}{lll}
1 & \text { Strongly in favour of better opportunities for Swiss citizens } & \text { if } y_{i}^{*} \leq \mu_{1} \\
2 & \text { Rather in favour of better opportunities for Swiss citizens } & \text { if } \mu_{1}<y_{i}^{*} \leq \mu_{2} \\
3 & \text { Neither of them } & \text { if } \mu_{2}<y_{i}^{*} \leq \mu_{3} \\
4 & \text { Rather in favour of equal opportunities for foreigners } & \text { if } \mu_{3}<y_{i}^{*} \leq \mu_{4} \\
5 & \text { Strongly in favour of equal opportunities for foreigners } & \text { if } \mu_{4}<y_{i}^{*}
\end{array}\right\}
$$

Foreigners recently settled in Switzerland are over-represented at both the bottom and particularly the top of the education distribution (compare Figure 2). Following labour market competition theory, we expect low and highly educated Swiss workers to be more opposed than those in the middle category. Accordingly, we formulate the following formal test of the labour market competition thesis:

5 Individual income is not controlled for in this analysis whereas it has been found to be an important determinant of individual preferences towards immigration in some previous studies (e.g. Facchini and Mayda 2009; Facchini and Mayda 2012). We have replicated all the estimation results after including the log of gross annual income from work (deflated into 2000 Swiss francs). Given the close correlation between income and education, the association between the log of income and the probability of having positive attitudes towards foreigners is generally not significant. In addition, the inclusion of the income variable does not alter the findings (compare Table 15 to Table 18 in the appendix).

6 Following Flückiger and Ramirez (2000) and de Coulon et al. (2003), a duration of 7 years has been attributed to workers with incomplete compulsory schooling; in terms of levels of schooling completed, these individuals have been included among those with primary or lower secondary education $(h=1)$. 
$\alpha_{1}<0$ and $\alpha_{3}<0$

As recognized by an increasing number of scholars (e.g. Scheve and Slaughter 2001; Hainmueller and Hiscox 2007), if education is highly correlated with individual values and beliefs, the relationship between the educational attributes of workers and their attitudes towards foreigners should have very little, if anything, to do with fears about labour market competition:

$\alpha_{1}=0$ and $\alpha_{3}=0$

Scheve and Slaughter (2001) propose two procedures to test whether education affects attitudes through non-economic factors. First, the baseline models are also estimated for the not-in-labour-force subsample; if the estimates associated with education deliver the same conclusion than those computed on the basis of the sample of workers, years or levels of schooling are probably unsatisfactory measures of labour market skills. Another check consists of extending the baseline models to account for indicators of individual values and beliefs such as opinions on Swiss tradition and trust in organisations for the defence of human rights. ${ }^{7}$ In addition, we perform sensitivity analysis in which we replace levels of education by levels of occupation using the 1-digit ISCO code condensed into four categories, as did Dumont and Monso (2007):

$y_{i}^{*}=\widetilde{\alpha}_{0} \widetilde{L}_{0 \mathrm{i}}+\widetilde{\alpha}_{1} \widetilde{L}_{1 \mathrm{i}}+\widetilde{\alpha}_{3} \widetilde{L}_{3 \mathrm{i}}+\mathbf{X}_{i} \boldsymbol{\beta}+\square \varepsilon_{i}$

where $\widetilde{L}_{0 i}$ is a binary variable for missing values, $\widetilde{L}_{1 \mathrm{i}}$ is a binary variable for jobs demanding low skills (=1 for ISCO category 9 ), $\widetilde{L}_{2 \mathrm{i}}$ is a binary variable for jobs demanding intermediate skills (=1 for ISCO categories 4 to 8 ) and $\widetilde{L}_{3 \mathrm{i}}$ is a binary variable for jobs demanding high skills ( $=1$ for ISCO categories 1 to 3 ). We use separate models that include levels of education and levels of occupation to directly relate to the different approaches common in the literature. At the same time, this approach demonstrates the robustness of the results - which will be immediately apparent from the juxtaposed figures and tables.

In line with Ortega and Polavieja (2012), we furthermore rely on an extended model to understand how risk of unemployment induces more exposure to labour market competition from foreigners:

$y_{i}^{*}=\alpha_{1} L_{1 \mathrm{i}}+\alpha_{3} L_{3 \mathrm{i}}+\gamma U_{i}+\mathbf{X}_{i} \boldsymbol{\beta}+\varepsilon_{i}$

7 These variables are not available in 2011, so we rely on other proxies for values and beliefs, namely general trust in people and political position. Both sets of values, used in 1999 and 2011, correspond to concepts highlighted by relevant theory. 
$y_{i}^{*}=\widetilde{\alpha}_{0} \widetilde{L}_{0 \mathrm{i}}+\widetilde{\alpha}_{1} \widetilde{L}_{1 \mathrm{i}}+\widetilde{\alpha}_{3} \widetilde{L}_{3 \mathrm{i}}+\gamma U_{i}+\mathbf{X}_{i} \boldsymbol{\beta}+\square \varepsilon_{i}$

where the self-assessed risk of unemployment in the following 12 months $U_{i}$, based on a scale from 0 ('no risk at all') to 10 ('a real risk'), is added as an additional variable to the models in equations (2) and (3). Swiss workers with a higher risk of unemployment are likely to be more exposed to labour market competition, and can thus be expected to have more negative attitudes towards foreigners:

$\gamma<0$

In order to investigate possible interactions between risk of unemployment and education, we also estimate the model on three subsamples: (i) individuals with (in)complete primary or lower secondary level education, (ii) those with upper secondary level education, and (iii) those with tertiary level education. As an additional robustness check, we provide estimates by level of occupation rather than education.

It is important to keep in mind that the risk of unemployment is unlikely to be randomly determined; in other words, this variable is probably endogenous in our equations and thus correlated with $\varepsilon_{i}$. Ignoring this endogeneity problem may lead to biased estimates of the attitudinal effects associated with the risk of unemployment. We test for endogeneity of $U_{i}$ using a similar version of the two-step approach developed by Rivers and Vuong (1988). Following Wooldridge (2010), we run the OLS regression $U_{i}$ on our control variables and the variable unemployment occurrence in the last 12 months as an instrument, ${ }^{8}$ save the residuals, and run the ordered probit $y_{i}$ on our control variables, $U_{i}$ and the residuals from the first step. The $t$ statistic on the latter is a valid test of the null hypothesis that $U_{i}$ is exogenous. Our choice of instrument is motivated by the well-documented scarring effects of unemployment experience on subsequent employment outcomes (e.g. Arulampalam, Booth, and Taylor 2000; Arulampalam, Gregg, and Gregory 2001; Gangl 2003). Accordingly, we expect a significant impact of unemployment occurrences in the previous year on the future risk of unemployment at work.

As a reminder, the hypotheses can be summarized as follows:

Hypothesis 1: Exposure to labour market competition is associated with negative attitudes, in particular for those at the bottom and top of the education distribution $\left(\alpha_{1}<0\right.$ and $\left.\alpha_{3}<0\right)$. The same applies if levels of education are replaced by levels of occupation $\left(\widetilde{\alpha}_{1}<0\right.$ and $\left.\widetilde{\alpha}_{3}<0\right)$.

Hypothesis 2: If individual values and beliefs are accounted for, there is no significant association between levels of education and attitudes towards foreigners $\left(\alpha_{1}=0\right.$ and $\left.\alpha_{3}=0\right)$.

8 Based on ordinal values of the variable 'unemployment occurrence in the last 12 months', we construct the following binary variable: no occurrence (reference category) vs. once or several times. 
Hypothesis 3: Individuals with an increased risk of unemployment are more likely to have negative attitudes towards foreigners $(\gamma<0)$.

\section{Findings}

In a first step, we examine the relationship between education and attitudes towards equal opportunities for immigrants. Ordered probit estimates from the baseline models are presented in Table 1. In line with prior research on the determinants of attitudes towards immigration, estimates from equation (1) in the first column show that the coefficient associated with years of education is significantly positive; this result is confirmed by estimates from equation (2) in the second column. Compared to middle educated workers, those with low levels of education tend to exhibit antiforeigner attitudes $\left(\alpha_{1}<0\right)$ while those with high levels of education tend to hold positive attitudes $\left(\alpha_{3}>0\right)$. This means that the labour competition argument, as specified in Hypothesis 1, seems to be relevant only among low educated workers. Most of the other estimates have the expected sign, in particular: having a mother or a father of foreign origin increases the propensity to exhibit positive attitudes towards foreigners.

The negative relationship between education and anti-foreigner attitudes may be attributed to the fact that individuals with low levels of education are more likely to be conservative in the sense of greater ties to Swiss tradition and lower trust in organisations for the defence of human rights (compare Kam 2012; Hatemi et al. 2011 for potential underlying mechanisms). When running the ordered probit regression on the subsample of those out of the labour force, we get substantively the same results as for the baseline models, regardless of whether the entire subsample or only retired people are considered. Indeed, as shown in Table 2, all estimates associated with years of schooling are significantly positive and those derived from equation (2) provide the same pattern of results. According to this initial set of checks, the educational variables seem to measure non-labour market considerations.

In a second series of procedures, we control for individual indicators of values and beliefs when estimating the baseline models. $F$ tests, reported in the last row of Table 3 , indicate that their inclusion is jointly significant. ${ }^{9}$ As presented in the fourth column of the same table, the coefficient associated with years of education is still significant when values and beliefs are taken into account. In contrast, when nonlinearity in educational attainment is considered, the significant relationship between a low level of education and attitudes vanishes $\left(\alpha_{1}=0\right)$, while the coefficient associated with a high level of education remains significantly positive. Replacing

9 As noted by Hainmueller and Hiscox (2007) and Ortega and Polavieja (2012) among others, indicators of individual values and beliefs might be endogenous, in the sense that the relationship between values/beliefs and education may result from concerns about labour market competition. To deal with this issue, we follow the procedure suggested by Hainmueller and Hiscox which consists of estimating levels of (a) trust in organisations for the defence of human rights, and (b) attachment to Swiss tradition using education as a predictor. If the indicators of individual values and beliefs are endogenous to labour market concerns, the relationship between these indicators and education should be significant among individuals in the labour force, but not significant among those out of the labour force. Table 14 in the appendix presents significant estimates of the same sign for the education variable among both subsamples, meaning that the association between values and education is not driven by labour market concerns. The same conclusion follows when education is replaced by occupation. 
levels of schooling with levels of occupation does not change the previous statement, in particular: Only the category of workers in jobs demanding high skills is associated with positive attitudes towards foreigners, whether or not we control for values and beliefs.

All in all, these findings indicate that the labour market competition hypothesis is rejected in favour of Hypothesis 2 since the strong relationship between a low level of education and anti-foreigner attitudes is mainly due to the omission of values and beliefs. This finding contrasts with Hello et al. (2006), who found that perceived threat (and not values or personality traits) are the most important factor explaining the educational effect on attitudes towards ethnic minorities among a Dutch sample of young adults. Here the insignificant attitudinal effects for low educated workers and those in low skilled jobs are consistent with results from recent studies on the wage impact of immigration in Switzerland (Gerfin and Kaiser 2010; Favre 2011) showing no evidence for negative wage effects in low skilled occupations. Favre argues that there is little room for downward adjustment of wages in low skill occupations since most of the latter are covered by collective agreements ensuring minimum wage protection. Put differently, immigration flows to Switzerland may simply not put native workers under pressure.

With respect to the remaining significant positive association between high levels of education/skills and positive attitudes, recall that our proxies only cover some aspects of relevant values and beliefs. For instance, workers with higher education may be more prone to have friends from different countries, a characteristic that we are not able to capture on the basis of our data. We are also unable to capture the tendency to control prejudice (Blinder, Ford, and Ivarsflaten 2013), which is more prevalent among those with higher levels of education. On the other hand, it could indeed be in the interest of skilled natives to ensure equal access for legally admitted migrants to the labour market more generally. Recent research has stressed the role of skilled migration in generating benefits for destination countries (e.g. Chiswick 1999; Hunt and Gauthier-Loiselle 2010; Kerr and Lincoln 2010; Stuen, Mobarak, and Maskus 2012). This is particularly relevant in the Swiss case where some professional fields are regularly experiencing shortages of qualified labour, despite increasing levels of highly skilled immigrants overall.

Table 1: Ordered probit model: baseline models with education

\begin{tabular}{lll}
\hline \multicolumn{1}{c}{ Equation } & \multicolumn{1}{c}{$(1)$} & $(2)$ \\
\hline$S$ : Years of schooling & $0.086^{* *}$ & \\
& $(0.007)$ & \\
$L_{2}$ (base) & & \\
$L_{1}$ : Compulsory education & & $-0.199^{* *}$ \\
& & $(0.054)$ \\
$L_{3}$ : Tertiary education & & $0.349^{* *}$ \\
& & $(0.040)$ \\
Male (base) & & \\
Female & 0.003 & 0.003 \\
& $(0.035)$ & $(0.035)$ \\
Age & $0.015^{*}$ & $0.017^{*}$ \\
& $(0.009)$ & $(0.009)$ \\
Age ${ }^{2}$ & $-0.000^{* *}$ & $-0.000^{* *}$ \\
& $(0.000)$ & $(0.000)$
\end{tabular}

Father: Swiss (base) 


\begin{tabular}{lll} 
Father: dual nationality & $0.306^{* *}$ & $0.318^{* *}$ \\
& $(0.135)$ & $(0.136)$ \\
Father: foreign nationality & $0.171^{* *}$ & $0.183^{* *}$ \\
& $(0.074)$ & $(0.073)$ \\
Father: missing nationality & 0.256 & 0.244 \\
& $(0.167)$ & $(0.165)$ \\
Mother: Swiss (base) & & \\
Mother: dual nationality & 0.130 & 0.132 \\
& $(0.082)$ & $(0.082)$ \\
Mother: foreign nationality & $0.191 * *$ & $0.200^{* *}$ \\
& $(0.076)$ & $(0.075)$ \\
Mother: missing nationality & 0.088 & 0.079 \\
& $(0.172)$ & $(0.171)$ \\
Canton dummies & Yes & Yes \\
\hline Observations & 4,222 & 4,222 \\
Percentage correctly predicted & $33.6 \%$ & $33.6 \%$ \\
\hline
\end{tabular}

Linearized standard errors in parentheses. $* * p<0.05, * p<0.10$

Source: Swiss Household panel, first wave in the SHP_I sample (1999).

Notes: Coefficient estimates, data are weighted. Dependent variable: attitudes towards equal opportunity for foreigners; the label 'compulsory education' captures primary and lower secondary education.

Table 2: Ordered probit mode: Active in the labour market (baseline models) vs. out of the labour force

\begin{tabular}{|c|c|c|c|c|c|c|}
\hline \multirow[b]{3}{*}{ Equation } & \multirow{2}{*}{\multicolumn{2}{|c|}{ Active in the labour market }} & \multicolumn{4}{|c|}{ Out of the labour force } \\
\hline & & & \multicolumn{2}{|c|}{ Total sample } & \multicolumn{2}{|c|}{65 years and older } \\
\hline & (1) & $(2)$ & (1) & (2) & (1) & (2) \\
\hline \multirow[t]{2}{*}{$S:$ Years of schooling } & $0.086^{* *}$ & & $0.061 * *$ & & $0.059^{* *}$ & \\
\hline & $(0.007)$ & & $(0.010)$ & & $(0.015)$ & \\
\hline \multicolumn{7}{|l|}{$L_{2}$ (base) } \\
\hline \multirow[t]{2}{*}{$L_{1}:$ Compulsory education } & & $-0.199 * *$ & & $-0.198 * *$ & & $-0.250 * *$ \\
\hline & & $(0.054)$ & & $(0.061)$ & & $(0.095)$ \\
\hline \multirow[t]{2}{*}{$L_{3}:$ Tertiary education } & & $0.349^{* *}$ & & $0.281^{* *}$ & & $0.253^{* *}$ \\
\hline & & $(0.040)$ & & $(0.075)$ & & $(0.109)$ \\
\hline Control variables & Yes & Yes & Yes & Yes & Yes & Yes \\
\hline Canton dummies & Yes & Yes & Yes & Yes & Yes & Yes \\
\hline Observations & 4,222 & 4,222 & 1,877 & 1,877 & 776 & 776 \\
\hline Percentage correctly predicted & $33.6 \%$ & $33.6 \%$ & $33.0 \%$ & $33.0 \%$ & $33.8 \%$ & $33.8 \%$ \\
\hline
\end{tabular}

Linearized standard errors in parentheses. ${ }^{* *} p<0.05,{ }^{*} p<0.10$

Source: Swiss Household panel, first wave in the SHP_I sample (1999).

Notes: Coefficient estimates, data are weighted. Dependent variable: attitudes towards equal opportunity for foreigners; the label 'compulsory education' captures primary and lower secondary education.

Table 3: Ordered probit model: Adding individual values and beliefs

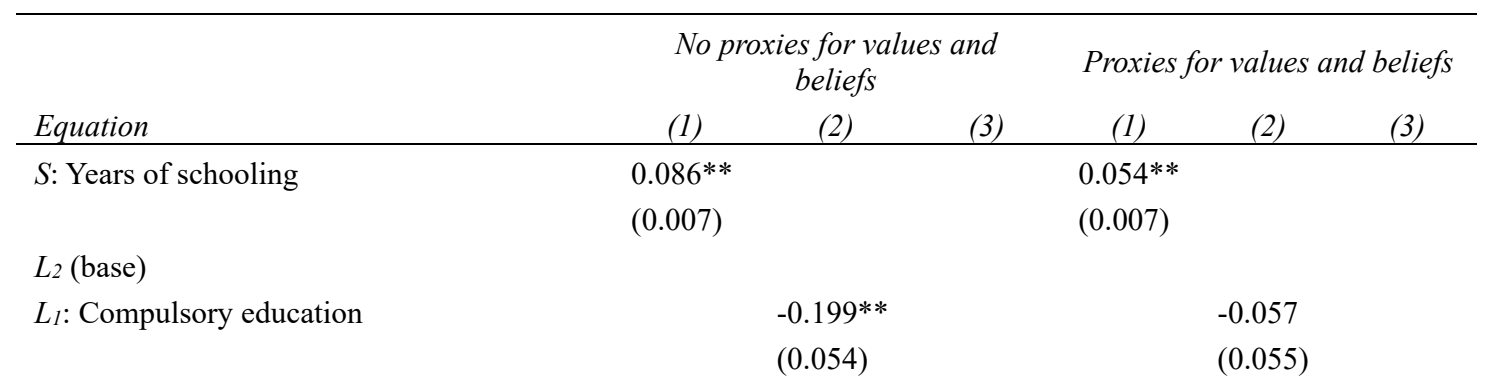




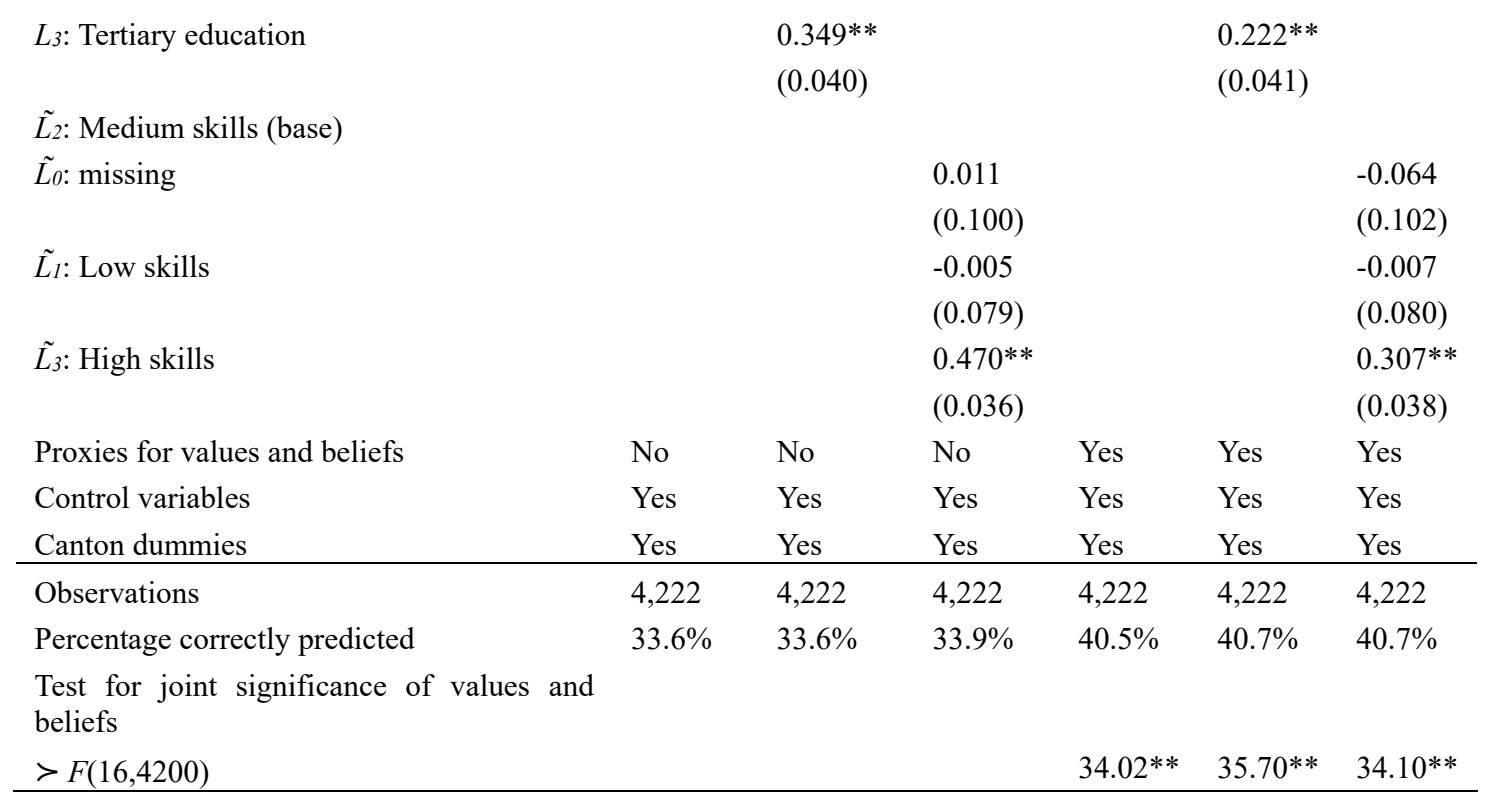

Linearized standard errors in parentheses. ${ }^{* *} p<0.05, * p<0.10$

Source: Swiss Household panel, first wave in the SHP_I sample (1999).

Notes: Coefficient estimates, data are weighted. Dependent variable: attitudes towards equal opportunity for foreigners; the label 'compulsory education' captures primary and lower secondary education.

\section{Risk of Unemployment}

Thus far we were unable to find clear support for the labour competition theory as stipulated in Hypothesis 1. Relying on education and occupation variables, however, provides an incomplete picture of the labour market exposure to foreign competitors. Accordingly, in this section we go a step further by including the risk of unemployment in the models in equations (2) and (3). As shown in the first column of Table 4 and Table 5 respectively, the findings outlined above remain valid when including individual risk of unemployment in the models: only workers with a tertiary education or in highly skilled occupations have significantly more positive attitudes towards foreigners than the middle category. Moreover, the risk of unemployment does not seem to be relevant in explaining attitudes towards foreigners in itself; its coefficient estimates are statistically insignificant and, a priori, Hypothesis 3 that the risk of unemployment matters for attitudes is rejected. However, estimating the ordered probit model separately for each level of education or occupation shows that the propensity to hold positive attitudes towards foreigners decreases with an increasing risk of unemployment only among highly educated workers or those in jobs demanding high skills (cf. second, third and fourth column in Table 4 and Table 5 respectively). This result is independent of whether values and beliefs are controlled for (cf. Table 12 and Table 13 in the appendix). ${ }^{10}$ In line with Hypothesis 3, among highly educated workers, attitudes towards foreigners become more negative with higher risk of unemployment. This finding is somewhat reminiscent of Facchini and Mayda (2012) who found, on the basis of the ESS data, that more educated natives are less likely to favour skilled immigration. Here we use a dependent variable more appropriate to capture labour force competition.

10 The results for all different subgroups are largely equivalent to those based on the entire sample when levels of education or occupation are interacted with the risk of unemployment (cf. Table 25 and Table 26 in the appendix). 
The impact of risk of unemployment on attitudes is highlighted in Figure 3 and Figure 4 where predicted probabilities for $y_{i}=1$ (i.e. strongly against equal opportunities) and $y_{i}=5$ (i.e. strongly in favour of equal opportunities) are plotted as a function of selfreported risk of unemployment by education or occupation level, respectively. All explanatory variables in $\mathbf{X}_{i}$ are set to their mean. While the highest change in predicted probabilities - visible by the steepest curve - is found among highly educated workers and those in jobs demanding high skills, there is no significant change with an increasing risk of unemployment when considering other levels of education or skills. As illustrated in Figure 3, for a ten-unit increase in unemployment risk (from 0 to 10), the highly educated see the predicted probability of being strongly against equal opportunities doubling from 0.05 to 0.1 whereas their predicted probability of being strongly in favour of equal opportunities decreases by more than 10 percentage points. The predicted probabilities by occupation level shown in Figure 4 lead to the same conclusions.

Table 4: Ordered probit model: Adding unemployment risk in equation (2)

\begin{tabular}{lllll}
\hline & & \multicolumn{3}{c}{ Education level } \\
\cline { 3 - 5 } Sample & All & $L_{1}$ & $L_{2}$ & $L_{3}$ \\
\hline$L_{2}$ (base) & & & & \\
$L_{1}:$ Compulsory education & -0.055 & & & \\
& $(0.056)$ & & & \\
$L_{3}$ : Tertiary education & $0.212^{* *}$ & & & \\
& $(0.041)$ & & & \\
U: Unemployment risk & -0.008 & 0.009 & -0.002 & $-0.037^{* *}$ \\
& $(0.007)$ & $(0.019)$ & $(0.009)$ & $(0.016)$ \\
Control variables & Yes & Yes & Yes & Yes \\
Canton dummies & Yes & Yes & Yes & Yes \\
Proxies for values and beliefs & Yes & Yes & Yes & Yes \\
\hline Observations & 4,090 & 537 & 2,412 & 1,141 \\
Percentage correctly predicted & $40.8 \%$ & $41.0 \%$ & $39.3 \%$ & $45.7 \%$ \\
\hline
\end{tabular}

Test for joint significance of the excluded instruments in the first stage

\begin{tabular}{lcccc}
$>F$ statistic & $46.3^{* *}$ & $6.8^{* *}$ & $29.6^{* *}$ & $12.4^{* *}$ \\
Test for exogeneity of $U_{i}$ & & & & \\
$>t$ statistic & -0.64 & -0.17 & -1.10 & 0.18 \\
\hline
\end{tabular}

Linearized standard errors in parentheses. ${ }^{* *} p<0.05,{ }^{*} p<0.10$

Source: Swiss Household panel, first wave in the SHP_I sample (1999).

Notes: Coefficient estimates, data are weighted. Dependent variable: attitudes towards equal opportunity for foreigners; the label 'compulsory education' captures primary and lower secondary education.

Table 5: Ordered probit model: Adding unemployment risk in equation (3)

\begin{tabular}{lllll}
\hline & & \multicolumn{3}{c}{ Occupation level } \\
\cline { 3 - 5 } Sample & All & $\tilde{L_{0}} \& \tilde{L_{1}}$ & $\tilde{L_{2}}$ & $\tilde{L_{3}}$ \\
\hline$\tilde{L_{2}}$ medium skills (base) & & & & \\
$\tilde{L_{0}}$ missing & -0.058 & & & \\
& $(0.112)$ & & & \\
$\tilde{L_{1}}$ Low skills & -0.004 & & & \\
& $(0.081)$ & & & \\
$\tilde{L_{3}}$ : High skills & $0.288^{* *}$ & & & \\
& $(0.038)$ & & & $-0.037^{* *}$ \\
$U:$ Unemployment risk & -0.008 & -0.006 & -0.011 &
\end{tabular}




\begin{tabular}{lllll} 
& $(0.007)$ & $(0.029)$ & $(0.010)$ & $(0.011)$ \\
Control variables & Yes & Yes & Yes & Yes \\
Canton dummies & Yes & Yes & Yes & Yes \\
Proxies for values and beliefs & Yes & Yes & Yes & Yes \\
\hline Observations & 4,090 & 305 & 1,651 & 2,134 \\
Percentage correctly predicted & $40.9 \%$ & $40.7 \%$ & $37.2 \%$ & $43.9 \%$ \\
\hline
\end{tabular}

Test for joint significance of the excluded instruments in the first stage

$>F$ statistic $45.7^{* *} \quad 6.3^{* *} \quad 24.1^{* *} \quad 18.3^{* *}$

Test for exogeneity of $U_{i}$

$>t$ statistic

$\begin{array}{llll}-1.18 & -0.28 \quad 0.62 & -1.30\end{array}$

Linearized standard errors in parentheses. $* * \mathrm{p}<0.05, * \mathrm{p}<0.10$

Source: Swiss Household panel, first wave in the SHP_I sample (1999).

Notes: Coefficient estimates, data are weighted. Dependent variable: attitudes towards equal opportunity for foreigners.

Figure 3: Predicted probabilities by level of education

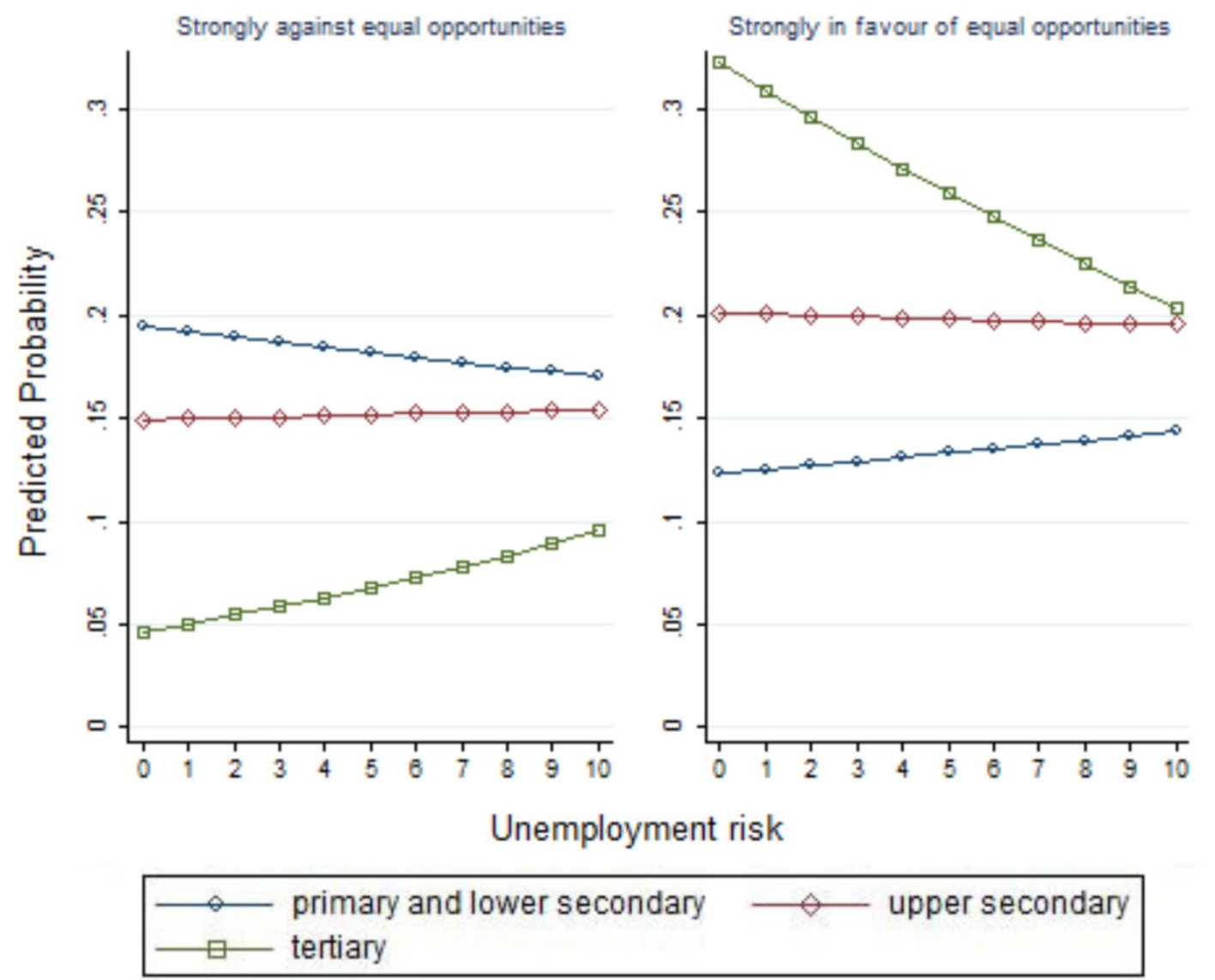

Note: Predicted probabilities for $y_{i}=1$ ('strongly in favour of better opportunities for Swiss citizens') and $y_{i}=5$ ('strongly in favour of equal opportunities for foreigners') based on estimates from Table 4 ( $2^{\text {nd }}, 3^{\text {rd }} \& 4^{\text {th }}$ columns) when all explanatory variables in $\mathbf{X}_{i}$ are set to their mean values. This figure corresponds to Figure 4 where the level of occupation is used. 
Figure 4: Predicted probabilities by level of occupation

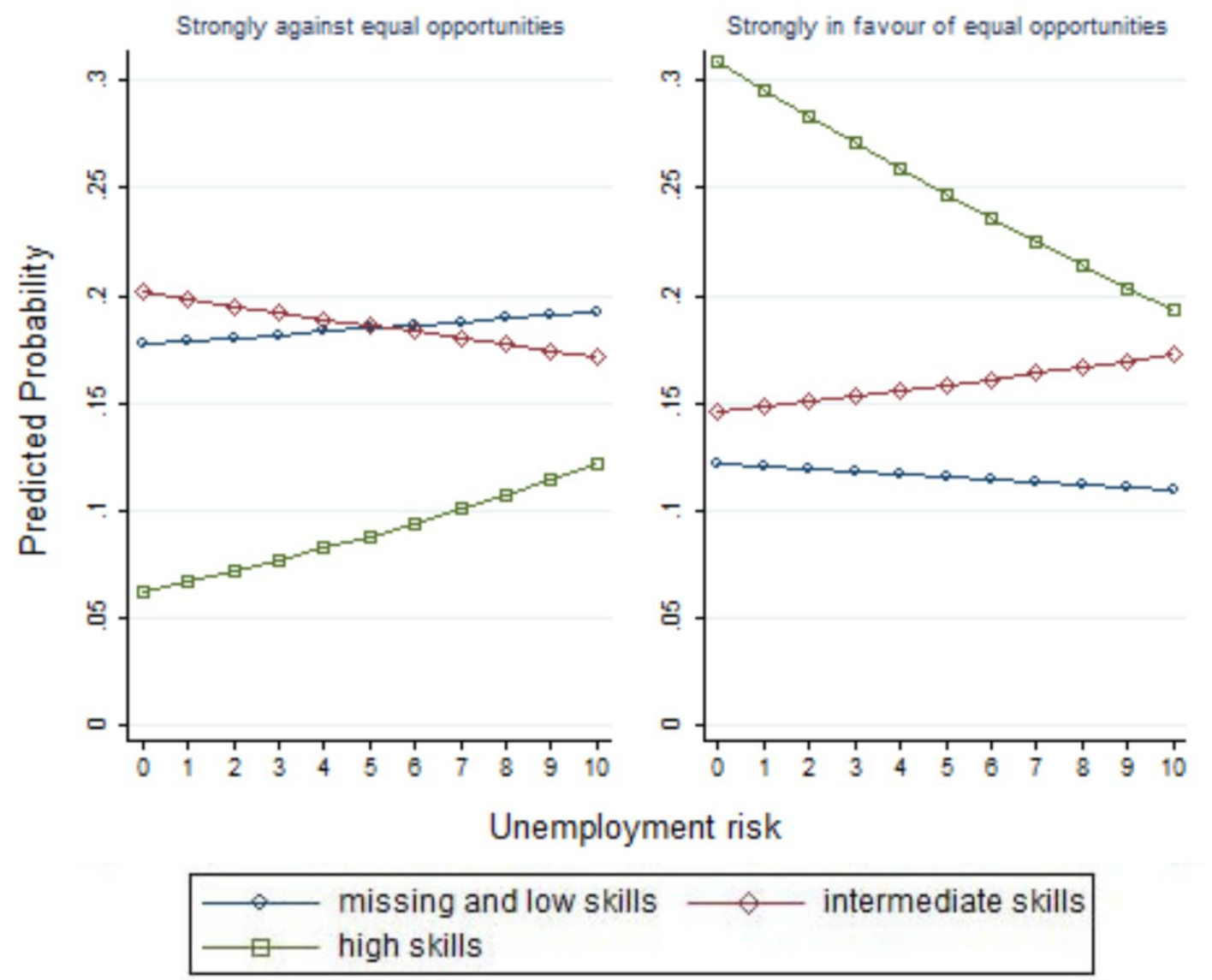

Note: Predicted probabilities for $y_{i}=1$ ('strongly in favour of better opportunities for Swiss citizens') and $y_{i}=5$ ('strongly in favour of equal opportunities for foreigners') based on estimates from Table 5 ( $2^{\text {nd }}, 3^{\text {rd }} \& 4^{\text {th }}$ columns) when all explanatory variables in $\mathbf{X}_{i}$ are set to their mean values. This figure corresponds to Figure 3 where the level of education is used.

As a final test, we consider endogeneity bias using the variable unemployment occurrence in the last 12 months as an instrumental variable. The result of the exogeneity test is presented at the bottom of Table 4 and Table 5 . It should be emphasized that our instrument is a significant predictor of $U_{i}$ in the first-stage equation, with most values of the $F$ statistic exceeding 10 (cf. penultimate rows). ${ }^{11}$ In addition, low values of the $t$ statistic indicate that the residuals in the second stage are never significant at a level of $10 \%$ (cf. last rows), meaning the null hypothesis of exogeneity is not rejected in all samples. Thus, there is no evidence of endogeneity bias in the estimated coefficients of $U_{i}$.

\section{Additional evidence from the ESS and WVS}

The attitudinal question in the SHP captures preferences with regard to equal opportunities for foreigners instead of focusing on respondents' desired level of immigration as is commonly done in the literature. In this section, we use data from the European Social Survey (ESS, round 1) and the World Value Survey (WVS,

11 Stock and Watson (2003) suggest a simple rule of thumb according to which a first-stage $F$ statistic lower than 10 indicates weak instruments, i.e. instruments in first-stage linear regressions are weakly correlated with the included endogenous variables. 
waves 3 and 5 combined) to examine to what extent the drivers of attitudes towards equal opportunities correspond to those of attitudes towards immigrants more generally. This will help to better understand the results presented and put them into perspective.

Both the ESS and the WVS include various questions on public opinion on immigration policy, and have been used in various studies like Mayda (2006) or Hainmueller and Hiscox (2007). We use two dependent variables from each survey. In the case of the ESS, we adopt the ordinal version of the variable used by Facchini and Mayda (2009) drawing on the individual perception about how many immigrants (of the same race and ethnic group as the majority) should be allowed in. The second variable for attitudes is a variation on the former, asking about immigrants belonging to a different race or ethnic group. In the case of the WVS, we use a question on immigration preferences already used by Mayda (2006), as well as a question more similar to the one used in this article: whether employers should give priority to natives over immigrants when jobs are scarce. With regard to the explanatory variables, it is important to note the following: years/levels of education and the ISCO code for occupation are available in the ESS, while the WVS only includes levels of education. We replicate ordered probit models on the basis of the baseline equations. Equations (1) to (3) can only be estimated using data from the ESS. Neither the ESS nor the WVS contain information on the individual risk of unemployment and we are unable to estimate equations ( $\left.2^{\prime}\right)$ and (3').

The results of three models using data from the ESS are presented in Table 6. The findings correspond to those reported in the main part of this article. In line with previous research, there is a significant positive association between education and pro-immigration attitudes. Indeed, as above, only the coefficient for tertiary education is significant (model 2). This is also true for model 3 which uses levels of occupation, and there are no substantive differences between the two dependent variables (i.e. whether the race/ethnicity of immigrants is the same as that of the majority population). Taken together, this is further evidence that Hypothesis 1 of labour market competition should be rejected, even without including controls for values and beliefs. In none of the models does the inclusion of income affect the predicted attitudes or any other variable in the model in a significant way.

Table 7 draws on data from the WVS and shows results that are more mixed. In particular, the statistical effect of education is different depending on whether attitudes refer to the desired level of immigration or to preference for hiring native workers. This complements findings by Jenssen and Engesbak (1994) who showed evidence for the multifaceted impact of education on Norwegian attitudes towards immigrants. Their results actually indicate that the impact of education varies as a function of the types of attitudes under consideration. In their analysis, the level of education is found to have a sizeable impact particularly when attitudes capture views about equal rights or stereotypic beliefs about immigrants. Here the results for hiring native workers (right-hand side of Table 7) are in line with those using the SHP: compared to Swiss-born workers with a middle level of education, only those with an upper level of education have significantly more positive attitudes once equation (2) include a full set of controls for values and beliefs. ${ }^{12}$ By contrast, adding proxies for

12 The way how values and beliefs are measured is very much data driven. While the chosen proxies in the ESS and the WVS are quite different from those in the SHP, most of them have been employed in the literature to control for individual values. For instance, Ortega and Polavieja (2012) 
values and beliefs in the models of attitudes towards immigration (left-hand side of Table 7) does not remove the statistical significance of education. Taken together, there is partial support for Hypothesis 1 (labour market competition) since, relative to the middle educated, only Swiss-born workers with a low level of education exhibit more negative attitudes. We note that the estimates for the relative income also differ according to the type of attitudes: While income deciles do not appear to influence attitudes towards equal opportunity at work, people in the second to sixth income deciles are less likely to express positive attitudes towards immigration compared to those in the lowest decile. This result may reflect welfare-related self interest where individuals with low to average income reject immigrants who could pose a burden on the welfare state. In any case, the relationship between relative income and attitudes towards immigration tends to be nonlinear.

Table 6: Ordered probit model: Education vs. occupation levels

\begin{tabular}{|c|c|c|c|c|c|c|}
\hline \multirow{3}{*}{$\begin{array}{l}\text { Dependent variable: Favour } \\
\text { immigration of } \\
\text { Equation } \\
S: \text { years of fulltime education } \\
\text { completed }\end{array}$} & \multicolumn{3}{|c|}{$\begin{array}{l}\text { same race/ethnic group as } \\
\text { majority }\end{array}$} & \multicolumn{3}{|c|}{$\begin{array}{l}\text { different race/ethnic group from } \\
\text { majority }\end{array}$} \\
\hline & $(1)$ & (2) & (3) & $(1)$ & (2) & (3) \\
\hline & $\begin{array}{l}0.066^{* *} \\
(0.012)\end{array}$ & & & $\begin{array}{l}0.078^{* *} \\
(0.012)\end{array}$ & & \\
\hline$L_{2}($ base $)$ & & & & & & \\
\hline$L_{0}$ : Other education & & $\begin{array}{c}0.356 \\
(0.239)\end{array}$ & & & $\begin{array}{l}0.711^{* *} \\
(0.181)\end{array}$ & \\
\hline$L_{1}:$ Compulsory education & & $\begin{array}{l}-0.052 \\
(0.111)\end{array}$ & & & $\begin{array}{l}-0.089 \\
(0.121)\end{array}$ & \\
\hline$L_{3}:$ Tertiary education & & $\begin{array}{l}0.533^{* *} \\
(0.089)\end{array}$ & & & $\begin{array}{l}0.540^{* *} \\
(0.088)\end{array}$ & \\
\hline$\tilde{L}_{\sim}:$ Medium skills (base) & & & & & & \\
\hline$\tilde{L} 0:$ missing & & & $\begin{array}{l}0.600^{* *} \\
(0.235)\end{array}$ & & & $\begin{array}{c}0.317 \\
(0.217)\end{array}$ \\
\hline$\tilde{L_{1}}:$ Low skills & & & $\begin{array}{l}-0.013 \\
(0.253)\end{array}$ & & & $\begin{array}{l}-0.164 \\
(0.236)\end{array}$ \\
\hline$\tilde{L_{3}}:$ High skills & & & $\begin{array}{l}0.462^{* *} \\
(0.082)\end{array}$ & & & $\begin{array}{l}0.476^{* *} \\
(0.081)\end{array}$ \\
\hline Household income: & & & & & & \\
\hline Less than $€ 150$ monthly (base) & & & & & & \\
\hline $150-300$ & $\begin{array}{c}0.179 \\
(0.886)\end{array}$ & $\begin{array}{c}0.253 \\
(0.848)\end{array}$ & $\begin{array}{c}0.194 \\
(0.818)\end{array}$ & $\begin{array}{c}0.328 \\
(0.665)\end{array}$ & $\begin{array}{c}0.358 \\
(0.571)\end{array}$ & $\begin{array}{c}0.282 \\
(0.583)\end{array}$ \\
\hline $300-500$ & $\begin{array}{l}-0.239 \\
(0.864)\end{array}$ & $\begin{array}{l}-0.075 \\
(0.825)\end{array}$ & $\begin{array}{l}-0.072 \\
(0.772)\end{array}$ & $\begin{array}{l}-0.369 \\
(0.739)\end{array}$ & $\begin{array}{l}-0.191 \\
(0.645)\end{array}$ & $\begin{array}{l}-0.220 \\
(0.645)\end{array}$ \\
\hline $500-1,000$ & $\begin{array}{c}0.067 \\
(0.921)\end{array}$ & $\begin{array}{c}0.188 \\
(0.870)\end{array}$ & $\begin{array}{c}0.082 \\
(0.855)\end{array}$ & $\begin{array}{c}0.181 \\
(0.842)\end{array}$ & $\begin{array}{c}0.282 \\
(0.747)\end{array}$ & $\begin{array}{c}0.237 \\
(0.804)\end{array}$ \\
\hline $1,000-1,500$ & $\begin{array}{c}0.125 \\
(0.875)\end{array}$ & $\begin{array}{c}0.188 \\
(0.841)\end{array}$ & $\begin{array}{c}0.212 \\
(0.766)\end{array}$ & $\begin{array}{l}-0.252 \\
(0.758)\end{array}$ & $\begin{array}{l}-0.158 \\
(0.663)\end{array}$ & $\begin{array}{l}-0.211 \\
(0.689)\end{array}$ \\
\hline $1,500-2,000$ & $\begin{array}{l}-0.077 \\
(0.844)\end{array}$ & $\begin{array}{l}-0.037 \\
(0.806)\end{array}$ & $\begin{array}{c}0.045 \\
(0.747)\end{array}$ & $\begin{array}{l}-0.252 \\
(0.715)\end{array}$ & $\begin{array}{l}-0.198 \\
(0.610)\end{array}$ & $\begin{array}{l}-0.163 \\
(0.616)\end{array}$ \\
\hline $2,000-2,500$ & $\begin{array}{l}-0.244 \\
(0.844)\end{array}$ & $\begin{array}{l}-0.222 \\
(0.800)\end{array}$ & $\begin{array}{l}-0.090 \\
(0.740)\end{array}$ & $\begin{array}{l}-0.124 \\
(0.680)\end{array}$ & $\begin{array}{l}-0.083 \\
(0.568)\end{array}$ & $\begin{array}{c}0.013 \\
(0.578)\end{array}$ \\
\hline $2,500-3,000$ & $\begin{array}{l}-0.466 \\
(0.833)\end{array}$ & $\begin{array}{l}-0.442 \\
(0.791)\end{array}$ & $\begin{array}{l}-0.352 \\
(0.731)\end{array}$ & $\begin{array}{l}-0.287 \\
(0.677)\end{array}$ & $\begin{array}{l}-0.251 \\
(0.566)\end{array}$ & $\begin{array}{l}-0.204 \\
(0.579)\end{array}$ \\
\hline $3,000-5,000$ & $\begin{array}{l}-0.235 \\
(0.826)\end{array}$ & $\begin{array}{l}-0.194 \\
(0.783)\end{array}$ & $\begin{array}{l}-0.132 \\
(0.724)\end{array}$ & $\begin{array}{l}-0.042 \\
(0.666)\end{array}$ & $\begin{array}{c}0.013 \\
(0.552)\end{array}$ & $\begin{array}{c}0.021 \\
(0.567)\end{array}$ \\
\hline $5,000-7,500$ & $\begin{array}{l}-0.033 \\
(0.827)\end{array}$ & $\begin{array}{c}-0.018 \\
(0.784)\end{array}$ & $\begin{array}{c}0.054 \\
(0.725)\end{array}$ & $\begin{array}{c}0.033 \\
(0.667)\end{array}$ & $\begin{array}{c}0.072 \\
(0.554)\end{array}$ & $\begin{array}{c}0.089 \\
(0.567)\end{array}$ \\
\hline
\end{tabular}

considered a rich set of variables reflecting various facets of values such as ideology, religiosity, happiness, trust and social capital. 


\begin{tabular}{lcccccc}
$7,500-10,000$ & 0.218 & 0.259 & 0.341 & 0.099 & 0.170 & 0.190 \\
More than 10,000 & $(0.839)$ & $(0.795)$ & $(0.737)$ & $(0.678)$ & $(0.566)$ & $(0.579)$ \\
& 0.146 & 0.225 & 0.338 & -0.133 & -0.013 & 0.061 \\
Missing & $(0.844)$ & $(0.800)$ & $(0.743)$ & $(0.686)$ & $(0.575)$ & $(0.588)$ \\
& -0.285 & -0.232 & -0.159 & -0.329 & -0.258 & -0.235 \\
Proxies for values and beliefs & $(0.826)$ & $(0.783)$ & $(0.723)$ & $(0.668)$ & $(0.553)$ & $(0.566)$ \\
Control variables & No & No & No & No & No & No \\
Canton dummies & Yes & Yes & Yes & Yes & Yes & Yes \\
\hline Observations & Yes & Yes & Yes & Yes & Yes & Yes \\
Percentage correctly predicted & 1099 & 1099 & 1099 & 1099 & 1099 & 1099 \\
\hline
\end{tabular}

Linearized standard errors in parentheses. $* * p<0.05, * p<0.10$

Source: European Social Survey 2002.

Notes: Coefficient estimates, data are weighted. The dependent variables are based on a 1 (allow none) to 4 (allow many immigrants to come and live in one's country) scale. $\tilde{L_{0}}$ includes individuals in armed forces or in missing occupations. Unreported control variables are a dummy for gender ( $=1$ if female, $=0$ otherwise), age, age squared, two dummies for father's place of birth (foreign-born, missing values, being Swiss-born as reference category), two dummies for mother's place of birth (foreign-born, missing values, being Swiss-born as reference category), five region dummies (Central Middleland, North Switzerland, Central Switzerland, West Switzerland, Ticino; Lake Geneva as reference category). Estimation results including controls for variables of values and beliefs, alike those used by Hainmueller and Hiscox (2007), lead to the same conclusions. Estimates associated with levels of education or occupation remain unchanged when excluding the income variable.

Table 7:Ordered probit model: Education, individual values and beliefs

\begin{tabular}{|c|c|c|c|c|c|c|}
\hline \multirow{2}{*}{$\begin{array}{l}\text { Dependent variables: } \\
\text { Equation }\end{array}$} & \multicolumn{3}{|c|}{ Pro-Immigration policy } & \multicolumn{3}{|c|}{$\begin{array}{l}\text { Equal job opportunity for } \\
\text { immigrants }\end{array}$} \\
\hline & (1) & $(2)$ & (3) & (1) & $(2)$ & (3) \\
\hline \multicolumn{7}{|l|}{$L_{2}:$ Middle level of education (base) } \\
\hline$L_{1}:$ Lower level of education & $\begin{array}{l}-0.465^{* *} \\
(0.133)\end{array}$ & $\begin{array}{l}-0.416^{* *} \\
(0.139)\end{array}$ & $\begin{array}{l}-0.377^{* *} \\
(0.137)\end{array}$ & $\begin{array}{c}-0.360^{* *} \\
(0.153)\end{array}$ & $\begin{array}{l}-0.278^{*} \\
(0.156)\end{array}$ & $\begin{array}{l}-0.233 \\
(0.157)\end{array}$ \\
\hline$L_{3}:$ Upper level of education & $\begin{array}{l}0.512^{* *} \\
(0.094)\end{array}$ & $\begin{array}{l}0.423^{* *} \\
(0.097)\end{array}$ & $\begin{array}{l}0.384^{* *} \\
(0.098)\end{array}$ & $\begin{array}{l}0.469^{* *} \\
(0.102)\end{array}$ & $\begin{array}{l}0.361^{* *} \\
(0.107)\end{array}$ & $\begin{array}{l}0.330^{* *} \\
(0.108)\end{array}$ \\
\hline \multicolumn{7}{|l|}{ Relative income: } \\
\hline \multicolumn{7}{|l|}{ Lowest decile (base) } \\
\hline \multirow{2}{*}{$2^{\text {nd }}$ decile } & $-0.613^{*}$ & $-0.630^{*}$ & $-0.701^{* *}$ & -0.417 & -0.311 & -0.385 \\
\hline & $(0.365)$ & $(0.370)$ & $(0.348)$ & $(0.331)$ & $(0.315)$ & $(0.314)$ \\
\hline \multirow[t]{2}{*}{$3^{\text {rd }}$ decile } & -0.485 & -0.402 & -0.426 & -0.064 & 0.172 & 0.143 \\
\hline & $\begin{array}{l}(0.324) \\
-0.784^{* *}\end{array}$ & $\begin{array}{c}(0.330) \\
-0.733^{* *}\end{array}$ & $\begin{array}{l}(0.312) \\
-0.741^{* *}\end{array}$ & $\begin{array}{c}(0.303) \\
-0.168\end{array}$ & $\begin{array}{c}(0.293) \\
0.009\end{array}$ & $\begin{array}{l}(0.291) \\
-0.042\end{array}$ \\
\hline $4^{\text {th }}$ decile & $\begin{array}{l}(0.318) \\
-0.655^{* *}\end{array}$ & $\begin{array}{l}(0.322) \\
-0.598^{*}\end{array}$ & $\begin{array}{l}(0.303) \\
-0.611^{* *}\end{array}$ & $\begin{array}{l}(0.297) \\
-0.336\end{array}$ & $\begin{array}{l}(0.283) \\
-0.172\end{array}$ & $\begin{array}{l}(0.280) \\
-0.220\end{array}$ \\
\hline $5^{\text {th }}$ decile & $\begin{array}{l}(0.313) \\
-0.521^{*}\end{array}$ & $\begin{array}{l}(0.317) \\
-0.450\end{array}$ & $\begin{array}{l}(0.296) \\
-0.491^{*}\end{array}$ & $\begin{array}{l}(0.289) \\
-0.156\end{array}$ & $\begin{array}{c}(0.277) \\
0.058\end{array}$ & $\begin{array}{l}(0.275) \\
-0.013\end{array}$ \\
\hline $6^{\text {th }}$ decile & $(0.315)$ & $(0.318)$ & $(0.297)$ & $(0.287)$ & $(0.274)$ & $(0.272)$ \\
\hline \multirow[t]{2}{*}{$7^{\text {th }}$ decile } & -0.258 & -0.117 & -0.238 & -0.035 & 0.257 & 0.139 \\
\hline & $(0.312)$ & $(0.316)$ & $(0.295)$ & $(0.291)$ & $(0.278)$ & $(0.279)$ \\
\hline \multirow[t]{2}{*}{$8^{\text {th }}$ decile } & -0.257 & -0.117 & -0.146 & 0.030 & 0.327 & 0.266 \\
\hline & $(0.319)$ & $(0.323)$ & $(0.301)$ & $(0.290)$ & $(0.278)$ & $(0.278)$ \\
\hline \multirow{2}{*}{$9^{\text {th }}$ decile } & $-0.557^{*}$ & -0.437 & -0.506 & -0.275 & -0.054 & -0.141 \\
\hline & $(0.325)$ & $(0.329)$ & $(0.308)$ & $(0.302)$ & $(0.289)$ & $(0.291)$ \\
\hline \multirow[t]{2}{*}{ Highest decile } & -0.439 & -0.426 & -0.521 & 0.066 & 0.211 & 0.127 \\
\hline & $(0.336)$ & $(0.344)$ & $(0.324)$ & $(0.303)$ & $(0.293)$ & $(0.292)$ \\
\hline \multirow[t]{2}{*}{ Missing } & -0.389 & -0.315 & -0.323 & -0.157 & 0.035 & -0.003 \\
\hline & $(0.317)$ & $(0.322)$ & $(0.303)$ & $(0.286)$ & $(0.272)$ & $(0.270)$ \\
\hline Proxies for values and beliefs & No & Partial & Full & No & Partial & Full \\
\hline Control variables & Yes & Yes & Yes & Yes & Yes & Yes \\
\hline Region dummies & Yes & Yes & Yes & Yes & Yes & Yes \\
\hline Observations & 1,170 & 1,170 & 1,170 & 1,170 & 1,170 & 1,170 \\
\hline
\end{tabular}




\begin{tabular}{|c|c|c|c|c|c|c|}
\hline Percentage correctly predicted & $60.00 \%$ & $60.51 \%$ & $61.11 \%$ & $58.55 \%$ & $61.88 \%$ & $62.22 \%$ \\
\hline $\begin{array}{l}\text { Test for joint significance of va } \\
\text { and beliefs }\end{array}$ & & & & & & \\
\hline$>F$ statistic & & $4.13 * *$ & $5.02 * *$ & & $4.73 * *$ & $3.99 * *$ \\
\hline
\end{tabular}

Linearized standard errors in parentheses. ${ }^{* *} p<0.05,{ }^{*} p<0.10$

Source: World Value Survey 1996-2007.

Notes: Coefficient estimates, data are weighted. The first dependent variable (let-hand side) is similar to those used in Table 6, taking four values from 1 (= prohibit people coming here from other countries) to 4 (= let anyone come who wants to). The second dependent variable (right-hand side) is similar to the one in the SHP survey, taking three values ( $=1$ if individuals disagree that employers should give priority to natives over immigrants when jobs are scarce, $=2$ if neither of them, $=3$ if individuals agree). The three levels of education are derived from the highest educational level attained. Unreported control variables are a dummy for gender $(=1$ if female, $=0$ otherwise), age, age squared, a dummy for 2007, two dummies for linguistic regions ('French', 'Italian', 'German' as reference category). The partial set of variables for values and beliefs are taken from Mayda (2006), namely political affiliation with the right (ranging from $1=$ 'left-wing' to $10=$ 'right-wing' and expressed in nine dummies for values from 2 to 10 , the reference category being 1, plus a dummy for missing values) and two dimensions of national pride (three dummies for values from $2=$ 'quite proud of own nationality' to $4=$ 'not at all proud', the reference category being 1 = 'very proud', plus a dummy for missing values; a dummy for the willingness to fight for one's country, the reference category being unwillingness, plus a dummy for missing values). In the full set of variables for values and beliefs, the partial set is complemented by two dummies for trust in people ('cannot be too careful in dealing with people', 'missing values', with 'most people can be trusted' as reference category) and four dummies for confidence in the United Nations ('quite a lot of confidence', 'not very much', 'none at all', 'missing values', with 'great deal of confidence' as reference category). Estimation results based on specifications in which the income variable is not controlled for deliver the same conclusions.

\section{Conclusion}

This paper has examined the labour market determinants of attitudes towards immigration, using cross-sectional data from the Swiss Household Panel survey. Contrary to the existing literature, we used an explicit measure of individual attitudes that captures preferences towards equal opportunities for foreign and Swiss citizen. This allows for a closer test of labour market competition than more common questions like whether more immigrants should be allowed to a country. The case of Switzerland was chosen because of its high share of foreign citizens and a clear concentration of immigrants in both low skilled and highly skilled occupations. This makes Switzerland an ideal case to study the labour market competition hypothesis, compared to countries where immigrants are concentrated at one end of the scale only. What is more, with low levels of unemployment, the effects of labour market competition outlined in this paper are likely to be more pronounced in other Western European countries, although only explicit tests will be able to confirm this.

While most existing studies use educational attainment to measure labour market skills, it is increasingly acknowledged that such an approach is likely to lead to incorrect conclusions. Indeed, Jenssen and Engesbak (1994) explored the multitude of educational effects on attitudes. In this article we reflect their argument and explicitly acknowledge that the level of education attained reflects non-economic unobservables in addition to actual skill endowment. For instance, we control for proxies of values and beliefs - opinions on Swiss tradition and trust in organisations for the defence of human rights - when estimating the attitudinal effects of education. When so doing, the analyses highlight that the commonly found association between low levels of education and negative attitudes towards immigration are likely a reflection of omitted variables. Indeed, once individual values and beliefs are accounted for in models that allow for nonlinear education effects, the impact of having a low level of education on anti-foreigner attitudes is no longer significant. Contrary to prediction by 
labour market competition theory and many existing studies, low educated workers do not exhibit anti-foreigner attitudes more than those with medium levels of education.

The situation is different for highly educated workers, who are a priori more likely to express positive views towards foreigners than their counterparts with an upper secondary education. This difference to individuals with medium levels of education can be found irrespective of the control for values and beliefs. Put differently, the variables of values and beliefs included in this article are unable to explain the attitudinal difference between individuals with upper secondary and tertiary education. In contrast to the other groups considered, however, highly educated workers tend to have more negative attitudes towards foreigners with an increasing risk of unemployment. This finding complements research by Ortega and Polavieja (2012) who showed that highly educated workers protected by more job-specific human capital tend to have more favourable attitudes towards immigrants. Given the low levels of unemployment in Switzerland, we assume that the magnitude of this effect is higher in other contexts. To assess the robustness of our findings, we have also replicated all results using levels of occupation rather than levels of education, and used alternative data sources. All in all, our results indicate that the labour market competition hypothesis does hold, but only for workers with a tertiary education or in highly skilled occupations.

Unlike most earlier studies, we account for nonlinearity in the relationship between education and attitudes since foreign workers are over-represented at both the bottom and the top of the educational distribution. This allows a more realistic test of labour force competition and leads to a more detailed account of the relationship between education and attitudes. Coenders and Scheepers (2003) suggest that the effects of education on attitudes are less significant in new democracies. It is unclear as to how this finding affects the nuanced picture presented in this article, and further research is needed in this regard - particularly research that illuminates the mechanism involved. The finding that highly educated and highly skilled individuals are affected by the risk of unemployment clearly suggest that education is more than a reflection of social desirability biases (Ostapczuk, Musch, and Moshagen 2009). While this article is unable to say anything about the origins of norms and ideology, variables capturing these non-economic factors are able to account for much of the attitudinal difference often attributed to education: Once ideological factors are taken into consideration, there is no significant difference between individuals with low levels of education and those with medium levels of education.

The analysis incorporating the self-assessed risk of unemployment to capture individual exposure to competition from foreigners suggests that the effects of education on attitudes are indeed multi-faceted. As an additional contribution to the literature, we interacted the risk of unemployment with the level of education in order to relax the assumption that the attitudinal impact of unemployment risk is the same for different educational levels. Similarly, the comparison of results with different dependent variables led to the insight that the predicted effect of education on attitudes towards immigration indeed differs between variables that capture attitudes towards labour force competition more directly. Put differently, the common view that education and attitudes are somewhat inherently linked - albeit due to unclear mechanisms - (e.g. Ceobanu and Escandell 2010; Hainmueller and Hopkins 2014) needs to be revised (see Jenssen and Engesbak 1994; Hello, Scheepers, and Sleegers 2006). 
On the whole, the findings in this article reveal that attitudes towards equal opportunities for foreigners cannot be entirely attributable to the skill composition of the foreign workforce within the labour market. Indeed, we have demonstrated that the strong link between a low level of education and negative attitudes towards foreigners is driven by differences in values and beliefs. At the same time, the positive link between high levels of education and positive attitudes towards foreigners hides a more complex picture, in which a higher risk of unemployment leads to less positive attitudes towards foreigners. With this, we find support for labour force competition theory, but only for specific groups: highly educated and highly skilled workers. At the other end of the skills scale, negative attitudes towards foreigners seem to be driven by individual values and beliefs. We would argue that economic and cultural explanations should not be seen as competing theories for attitudes towards foreigners, but as complementary mechanism that affect different parts of the population in distinct ways.

\section{References}

Arulampalam, Wiji, Alison L Booth, and Mark P Taylor. 2000. "Unemployment Persistence." Oxford Economic Papers 52 (1): 24-50.

Arulampalam, Wiji, Paul Gregg, and Mary Gregory. 2001. "Unemployment Scarring." Economic Journal 111 (475): F577-584.

Blinder, Scott, Robert Ford, and Elisabeth Ivarsflaten. 2013. "The Better Angels of Our Nature: How the Antiprejudice Norm Affects Policy and Party Preferences in Great Britain and Germany." American Journal of Political Science 57 (4): 841-57. doi:10.1111/ajps.12030.

Blumer, Herbert. 1958. "Race Prejudice as a Sense of Group Position." The Pacific Sociological Review 1 (1): 3-7.

Bobo, Lawrence, and Vincent L. Hutchings. 1996. "Perceptions of Racial Group Competition: Extending Blumer's Theory of Group Position to a Multiracial Social Context." American Sociological Review, 951-72.

Borjas, George J. 1999. Heaven's Door: Immigration Policy and the American Economy. Princeton: Princeton University Press.

Borjas, George J., Richard B. Friedman, and Lawrence F. Katz. 1997. "How Much Do Immigration and Trade Affect Labor Market Outcomes?" Brookings Papers on Economic Activity 28 (1): 1-90.

Bornschier, Simon. 2010. Cleavage Politics and the Populist Right: The New Cultural Conflict in Western Europe. Philadelphia: Temple University Press.

Ceobanu, Alin M., and Xavier Escandell. 2010. "Comparative Analyses of Public Attitudes Toward Immigrants and Immigration Using Multinational Survey Data: A Review of Theories and Research." Annual Review of Sociology 36 (1): 309-28.

Chiswick, Barry R. 1999. “Are Immigrants Favorably Self-Selected?" American Economic Review 89 (2): 181-85.

Coenders, Marcel, and Peer Scheepers. 1998. "Support for Ethnic Discrimination in the Netherlands 1979-1993: Effects of Period, Cohort, and Individual Characteristics." European Sociological Review 14 (4): 405-22.

2003. "The Effect of Education on Nationalism and Ethnic Exclusionism: An International Comparison." Political Psychology 24 (2): 313-43.

Coulon, Augustin de, Jean-Marc Falter, Yves Flückiger, and J. Ramirez. 2003. "Analyse des différences de salaires entre population suisse et étrangère." In 
Les migrations et la Suisse, edited by Hans-Rudolf Wicker, Rosita Fibbi, and Werner Haug, 263-88. Zurich: Seismo.

Dancygier, Rafaela M., and David D. Laitin. 2014. "Immigration into Europe: Economic Discrimination, Violence, and Public Policy." Annual Review of Political Science 17 (1). doi:10.1146/annurev-polisci-082012-115925.

Dülmer, H., and M. Klein. 2005. "Extreme Right-wing Voting in Germany in a Multilevel Perspective: A Rejoinder to Lubbers and Scheepers." European Journal of Political Research 44 (2): 243-63.

Dumont, Jean-Christophe, and Olivier Monso. 2007. "Matching Educational Background and Employment: A Challenge for Immigrants In Host Countries." SourceOECD Transition Economies, 156-96.

Espenshade, Thomas J., and Katherine Hempstead. 1996. "Contemporary American Attitudes Toward U.S. Immigration.” International Migration Review 30 (2): 535-70.

ESS. 2012. European Social Survey (ESS-5). Bergen: European Social Survey Data Archive, Norwegian Social Science Data Services.

Facchini, Giovanni, and Anna Maria Mayda. 2009. "Does the Welfare State Affect Individual Attitudes Toward Immigrants? Evidence Across Countries." The Review of Economics and Statistics 91 (2): 295-314.

2012. "Individual Attitudes Towards Skilled Migration: An Empirical Analysis Across Countries." The World Economy 35 (2): 183-96.

Facchini, Giovanni, Anna Maria Mayda, and Riccardo Puglisi. 2013. "Individual Attitudes Towards Immigration: Economic Vs. Non-economic Determinants." In Immigration and Public Opinion in Liberal Democracies, edited by Gary P. Freeman, Randall Hansen, and David L. Leal. Routledge.

Favre, Sandro. 2011. "The Impact of Immigration on the Wage Distribution in Switzerland." Working Paper Series, Department of Economics, University of Zurich 22.

Felbermayr, Gabriel J., and Wilhelm Kohler. 2007. "Immigration And Native Welfare." International Economic Review 48 (3): 731-60.

Flückiger, Yves, and José Vincent Ramirez. 2000. Analyse comparative des salaires entre les hommes et les femmes sur la base des enquêtes sur la structure des salaires de la LSE 1994 et 1996. Bureau fédéral de l'égalité entre femmes et hommes.

Gangl, M. 2003. "Welfare States and the Scar Effects of Unemployment: A Comparative Analysis of the United States and West Germany." American Journal of Sociology 109: 1319-64.

Gerfin, Michael, and Boris Kaiser. 2010. "The Effects of Immigration on Wages: An Application of the Structural Skill-Cell Approach." Swiss Journal of Economics and Statistics 146 (IV): 709-39.

Graf, E. 2009. Weightings of the Swiss Household Panel: SHP_1 Wave 9, SHP II Wave 4, SHP_I and SHP_II Combined. Swiss Statistics: Statistical Base and Overviews. Neuchâtel: Swiss Federal Statistical Office. http://books.google.ch/books?id=QHqBKQEACAAJ.

Green, Eva GT, Nicole Fasel, and Oriane Sarrasin. 2010. "The More the Merrier? The Effects of Type of Cultural Diversity on Exclusionary Immigration Attitudes in Switzerland." International Journal of Conflict and Violence 4 (2): 177-90.

Hainmueller, Jens, and Michael J. Hiscox. 2007. "Educated Preferences: Explaining Attitudes Toward Immigration in Europe." International Organization 61 (02): 399-442. 
Hainmueller, Jens, and Daniel J. Hopkins. 2014. "Public Attitudes Toward Immigration." Annual Review of Political Science 17. http://papers.ssrn.com/abstract=2289270.

Hatemi, Peter K., Nathan A. Gillespie, Lindon J. Eaves, Brion S. Maher, Bradley T. Webb, Andrew C. Heath, Sarah E. Medland, et al. 2011. "A Genome-Wide Analysis of Liberal and Conservative Political Attitudes." The Journal of Politics 73 (1): 271-85. doi:10.1017/S0022381610001015.

Helbling, M. 2011. "Why Swiss-Germans Dislike Germans: Opposition to Culturally Similar and Highly Skilled Immigrants." European Societies 13 (1): 5-27.

Hello, Evelyn, Peer Scheepers, and Peter Sleegers. 2006. "Why the More Educated Are Less Inclined to Keep Ethnic Distance: An Empirical Test of Four Explanations." Ethnic and Racial Studies 29 (5): 959-85.

Honegger, L. 2011. "Reimann: «Die Stiefel auf dem Plakat erinnerten mich an NaziStiefel»." Aargauer Zeitung, November 29, sec. Schweiz. http://www.aargauerzeitung.ch/schweiz/artikel-116637737.

Hunt, Jennifer, and Marjolaine Gauthier-Loiselle. 2010. "How Much Does Immigration Boost Innovation?" American Economic Journal: Macroeconomics 2 (2): 31-56.

Huth, Petra. 2004. Marché Du Travail En Suisse - Salaires Élevés et Faible Réglementation. Economic Briefing 37. Credit Suisse, Economic \& Policy Consulting.

Jenssen, Anders Todal, and Heidi Engesbak. 1994. "The Many Faces of Education: Why Are People with Lower Education More Hostile Towards Immigrants Than People with Higher Education?" Scandinavian Journal of Educational Research 38 (1): 33-50.

Kahn, Lawrence M. 2004. "Immigration, Skills and the Labor Market: International Evidence." Journal of Population Economics 17 (3): 501-34.

Kam, C. 2012. "Risk Attitudes and Political Participation." American Journal of Political Science. doi:10.1111/j.1540-5907.2012.00605.x.

Kerr, William R., and William F. Lincoln. 2010. "The Supply Side of Innovation: H1B Visa Reforms and U.S. Ethnic Invention." Journal of Labor Economics 28 (3): 473-508.

Kessler, A. 2001. Immigration, Economic Insecurity, and the "Ambivalent" American Public. Working Paper 41. The Center for Comparative Immigration Studies.

Lipps, O., and U. Kuhn. 2009. Codebook for CNEF Variables in the SHP (1999 2007) Data Documentation. SHP Working Papers 5_09. Swiss Centre of Expertise in the Social Sciences (FORS). http://aresoas.unil.ch/workingpapers/WP5_09.pdf.

Malhotra, N., Y. Margalit, and C. Mo. 2013. "Economic Explanations for Opposition to Immigration: Distinguishing Between Prevalence and Conditional Impact." American Journal of Political Science. doi:10.1111/ajps.12012.

Mayda, Anna Maria. 2006. "Who Is Against Immigration? A Cross-Country Investigation of Individual Attitudes Toward Immigrants." The Review of Economics and Statistics 88 (3): 510-30.

Müller, T., and S. Tai. 2010. "Individual Attitudes Towards Migration: A Reexamination of the Evidence". presented at the 25th Annual Meeting of the European Economic Association, Glasgow, May 17. http://www.unifr.ch/controlling/seminar/2009-2010/Mueller_Tai_Genf.pdf. 
O'Rourke, Kevin H., and Richard Sinnott. 2006. "The Determinants of Individual Attitudes Towards Immigration." European Journal of Political Economy 22 (4): 838-61.

Ortega, Francesc, and Javier G. Polavieja. 2012. "Labor-market Exposure as a Determinant of Attitudes Toward Immigration." Labour Economics 19 (3): 298-311.

Ostapczuk, Martin, Jochen Musch, and Morten Moshagen. 2009. “A Randomizedresponse Investigation of the Education Effect in Attitudes Towards Foreigners." European Journal of Social Psychology 39 (6): 920-31.

Pecoraro, Marco. 2005. "Les Migrants Hautement Qualifiés." In Migrants et Marché Du Travail. Compétences et Insertion Professionnelle Des Personnes D'origine Étrangère En Suisse, edited by Werner Haug and Philippe Wanner, 71-110. 6. Neuchâtel: Office fédéral de la statistique.

Rivers, Douglas, and Quang H. Vuong. 1988. "Limited Information Estimators and Exogeneity Tests for Simultaneous Probit Models." Journal of Econometrics 39 (3): 347-66.

Ruedin, Didier. 2013. "Obtaining Party Positions on Immigration in Switzerland: Comparing Different Methods.” Swiss Political Science Review 19 (1): 84105. doi:10.1111/spsr.12018.

Ruedin, Didier, and Gianni D'Amato. 2015. "Politicisation of Immigration in Switzerland: The Importance of Direct Democracy." In The Politicisation of Immigration, edited by Wouter van der Brug, Gianni D’Amato, Joost Berkhout, and Didier Ruedin. Abingdon: Routledge.

Schellenbauer, Patrick, Rudolf Walser, Daniela Lepori, Beatz Hotz-Hart, and Philipp Gonon. 2010. "Die Zukunft Der Lehre: Die Berufsbildung in Einer Neuen Wirklichkeit" Avenir Suisse, Zurich.

Scheve, Kenneth F., and Matthew J. Slaughter. 2001. "Labor Market Competition and Individual Preferences over Immigration Policy." The Review of Economics and Statistics 83 (1): 133-45.

Schneider, S. 2008. "Anti-immigrant Attitudes in Europe: Outgroup Size and Perceived Ethnic Threat." European Sociological Review 24 (1): 53-67. doi:10.1093/esr/jem034.

Semyonov, Moshe, Rebeca Raijman, Anat Yom Tov, and Pater Schmid. 2004. "Population Size, Perceived Threat, and Exclusion: A Multiple-indicators Analysis of Attitudes Toward Foreigners in Germany." Social Science Research 33: 681-701. doi:10.1016/j.ssresearch.2003.11.003.

Sherif, Muzafer, and Carolyn W. Sherif. 1953. Groups in Harmony and Tension; an Integration of Studies of Intergroup Relations. Oxford: Harper \& Brothers. http://psycnet.apa.org/psycinfo/1954-02446-000.

SHP. 2012. Swiss Household Panel [Data File]. Lausanne: FORS. http://www.swisspanel.ch.

Sides, John, and Jack Citrin. 2007. "European Opinion About Immigration: The Role of Identities, Interests and Information." British Journal of Political Science 37 (3): 477.

Skenderovic, Damir, and Gianni D'Amato. 2008. Mit Dem Fremden Politisieren Rechtspopulistische Parteien Und Migrationspolitik in Der Schweiz Seit Den 1960er Jahren. Zürich: Chronos.

Stock, James H, and Mark W Watson. 2003. Introduction to Econometrics. Vol. 104. Addison Wesley New York. 
Stuen, Eric T., Ahmed Mushfiq Mobarak, and Keith E. Maskus. 2012. "Skilled Immigration and Innovation: Evidence from Enrolment Fluctuations in US Doctoral Programmes." The Economic Journal 122 (565): 1143-76.

Wooldridge, Jeffrey M. 2010. Econometric Analysis of Cross Section and Panel Data. MIT Press Books 0262232588. Cambridge: The MIT Press.

World Values Survey Association. 2009. World Value Survey (Release 20090901). Institute for Social Research. http://www.worldvaluessurvey.org/.

Zimmerli, Walther Ch., Carlo Malaguerra, Rudolf Künzli, and Markus Fischer. 2009. "Une Éducation Pour La Suisse Du Futur, Exigences Posées Au Système Éducatif Suisse En 2030" Académie suisse des sciences, Berne.

\section{Appendix}

Table 8: Individuals from 1999 retained in the empirical analysis

\begin{tabular}{|c|c|c|c|c|c|c|}
\hline \multirow[b]{4}{*}{ Selection criteria } & \multicolumn{6}{|c|}{ Sample/Year } \\
\hline & \multicolumn{6}{|c|}{ SHP_I/1999 } \\
\hline & \multicolumn{2}{|c|}{$\begin{array}{l}\text { Active in the labour } \\
\text { market }\end{array}$} & \multicolumn{4}{|c|}{ Out of the labour force } \\
\hline & Individuals & $\%$ & $\begin{array}{l}\text { Total sample } \\
\text { Individuals }\end{array}$ & $\%$ & $\begin{array}{l}65 \& \text { older } \\
\text { Individuals }\end{array}$ & $\%$ \\
\hline Individual interview completed & 5,172 & 100 & 2,498 & 100 & 845 & 100 \\
\hline Registered Swiss voters & 4,378 & 84.6 & 1,958 & 78.5 & 804 & 95.1 \\
\hline $\begin{array}{l}\text { Valid information on attitudes towards } \\
\text { foreigner }\end{array}$ & 4,222 & 81.6 & 1,877 & 75.1 & 776 & 91.8 \\
\hline $\begin{array}{l}\text { Valid information on risk of } \\
\text { unemployment }\end{array}$ & 4,090 & 79.1 & & & & \\
\hline
\end{tabular}

Source: Swiss Household Panel, first wave in the SHP_I sample, data are unweighted.

Table 9: Conversion scale between levels and years of schooling

\begin{tabular}{ll}
\hline Description & Years of schooling \\
\hline Primary and lower secondary levels & \\
Compulsory school, elementary vocational training & 9 \\
Domestic science course, 1 year school of commerce & 10 \\
Upper secondary level & \\
General training school & 12 \\
Apprenticeship & 12 \\
Fulltime vocational school & 12 \\
Maturity (high school) & 12 \\
Tertiary level & \\
Technical or vocational school & 15 \\
Higher vocational college & 15 \\
University & 18 \\
PhD & 21 \\
\hline
\end{tabular}

Source: Codebook for CNED variables in the SHP (Lipps and Kuhn 2009).

Table 10: Explanatory variables included in the empirical analysis for 1999

\begin{tabular}{l} 
Continuous variables \\
\hline Variable \\
\hline Years of education $(S)$ \\
Age in years (at the time of the interview) \\
Age squared
\end{tabular}


Risk of unemployment in the following 12 months $(0,1, \ldots, 10)$

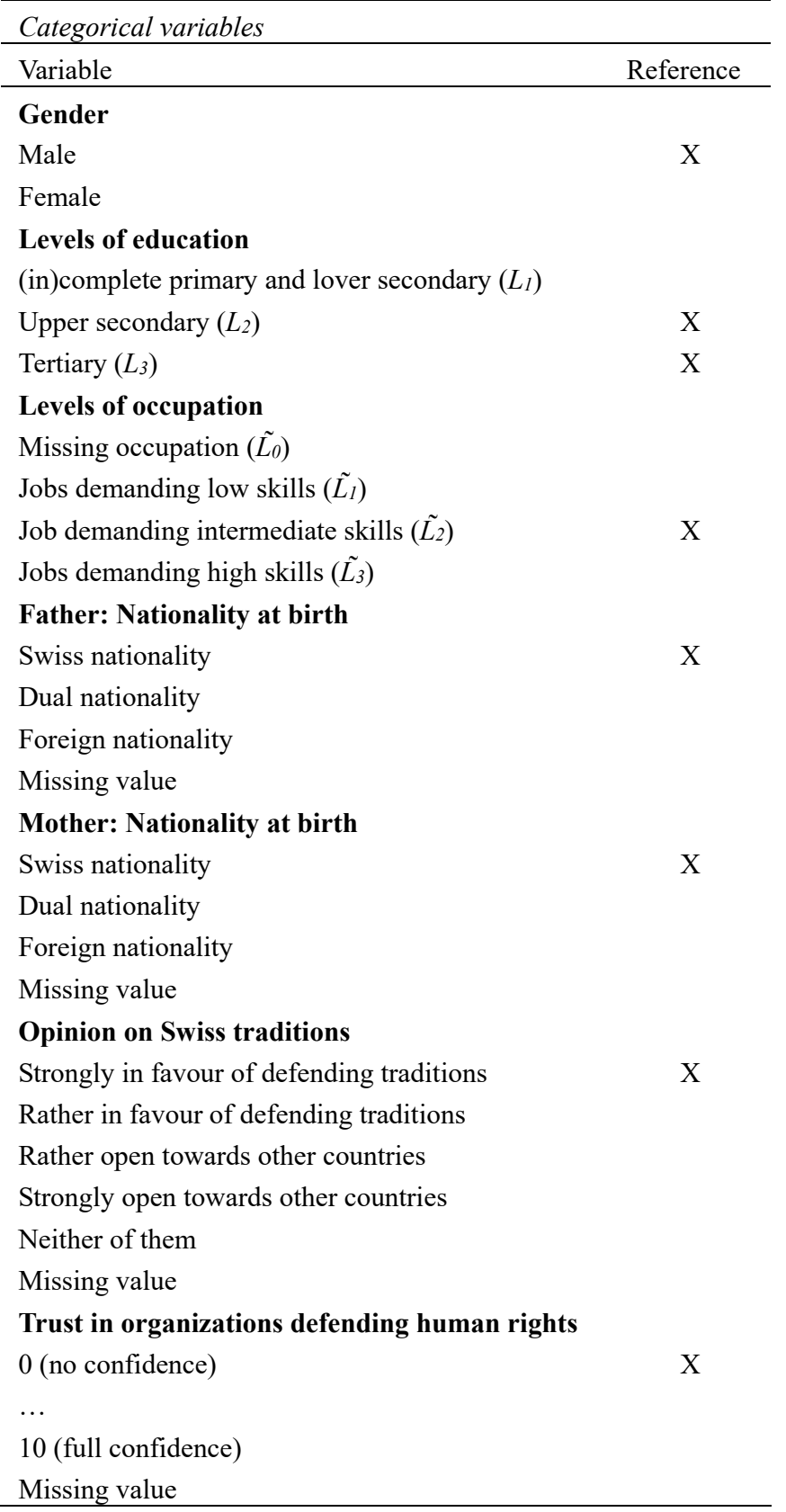

Table 11: Summary statistics for 1999

\begin{tabular}{|c|c|c|c|c|}
\hline \multirow{2}{*}{ Variable } & \multirow{2}{*}{ Mean } & \multirow{2}{*}{ Linearized S.E. } & \multicolumn{2}{|c|}{$95 \%$ C.I. } \\
\hline & & & Lower & Upper \\
\hline$y_{i}=1$ & 0.1608761 & 0.0057755 & 0.1495531 & 0.1721992 \\
\hline$y_{i}=2$ & 0.1784000 & 0.0060009 & 0.1666351 & 0.1901650 \\
\hline$y_{i}=3$ & 0.0971861 & 0.0046759 & 0.0880188 & 0.1063534 \\
\hline$y_{i}=4$ & 0.3166985 & 0.0073206 & 0.3023463 & 0.3310508 \\
\hline$y_{i}=5$ & 0.2468392 & 0.0067239 & 0.2336567 & 0.2600216 \\
\hline$S_{i}$ : Years of schooling & 12.906230 & 0.0416415 & 12.824590 & 12.987870 \\
\hline$L_{1 i}$ : Compulsory education & 0.1352820 & 0.0053964 & 0.1247022 & 0.1458617 \\
\hline$L_{2 i}:$ Upper secondary education & 0.5826827 & 0.0077678 & 0.5674537 & 0.5979118 \\
\hline$L_{3 i}:$ Tertiary education & 0.2820353 & 0.0071061 & 0.2681036 & 0.2959670 \\
\hline$\tilde{L_{0}}$ : Missing occupation & 0.0332058 & 0.0028549 & 0.0276088 & 0.0388028 \\
\hline$\tilde{L}_{1 i}:$ Low skills & 0.0477776 & 0.0033813 & 0.0411484 & 0.0544068 \\
\hline
\end{tabular}




\begin{tabular}{lllll}
$\tilde{L_{2 i}}$ : Intermediate skills & 0.4034345 & 0.0076877 & 0.3883626 & 0.4185064 \\
$\tilde{L}_{3 i}:$ High skills & 0.5155822 & 0.0078250 & 0.5002411 & 0.5309232 \\
Female & 0.4561178 & 0.0077708 & 0.4408830 & 0.4713526 \\
Age & 42.307600 & 0.2129871 & 41.890030 & 42.725170 \\
Father: Swiss nationality & 0.8423333 & 0.0056971 & 0.8311640 & 0.8535027 \\
Father: dual nationality & 0.0207178 & 0.0022695 & 0.0162684 & 0.0251672 \\
Father: foreign nationality & 0.1072982 & 0.0048472 & 0.0977952 & 0.1168012 \\
Father: missing nationality & 0.0296506 & 0.0025951 & 0.0245629 & 0.0347384 \\
Mother: Swiss nationality & 0.8083484 & 0.0061339 & 0.7963228 & 0.820374 \\
Mother: dual nationality & 0.0511010 & 0.0034551 & 0.0443271 & 0.0578748 \\
Mother: foreign nationality & 0.1134897 & 0.0049382 & 0.1038082 & 0.1231713 \\
Mother: missing nationality & 0.0270609 & 0.0024736 & 0.0222114 & 0.0319104 \\
$U_{i}:$ Unemployment risk & 1.7010350 & 0.0394802 & 1.6236330 & 1.7784380 \\
\hline
\end{tabular}

Source: Swiss Household Panel, first wave in the SHP_I sample (1999).

Notes: Data are weighted; all mean values are calculated based on $N=4,222$, except for $U_{i}$ (based on $N=4,090$ ).

Table 12: ordered probit model: Adding unemployment risk in equation (2)

\begin{tabular}{lllll}
\hline & & \multicolumn{3}{c}{ Education level } \\
\cline { 3 - 5 } Sample & All & $L_{1}$ & $L_{2}$ & $L_{3}$ \\
\hline$L_{2}$ (base) & & & & \\
$L_{1}$ : Compulsory education & $-0.196^{* *}$ & & & \\
& $(0.055)$ & & & \\
$L_{3}$ : Tertiary education & $0.344^{* *}$ & & & \\
& $(0.040)$ & & & \\
U: Unemployment risk & -0.010 & 0.008 & -0.003 & $-0.032^{* *}$ \\
& $(0.007)$ & $(0.017)$ & $(0.009)$ & $(0.015)$ \\
Control variables & Yes & Yes & Yes & Yes \\
Canton dummies & Yes & Yes & Yes & Yes \\
Proxies for values and beliefs & No & No & No & No \\
\hline Observations & 4,090 & 537 & 2,412 & 1,141 \\
Percentage correctly predicted & $33.7 \%$ & $33.6 \%$ & $31.2 \%$ & $40.7 \%$ \\
\hline
\end{tabular}

Test for joint significance of the excluded instruments in the first stage

\begin{tabular}{lcccc}
$>F$ statistic & $46.5^{* *}$ & $7.3^{* *}$ & $28.6^{* *}$ & $12.0^{* *}$ \\
$\begin{array}{l}\text { Test for exogeneity of } U_{i} \\
>t \text { statistic }\end{array}$ & -0.38 & 0.30 & -0.78 & 0.34 \\
\hline
\end{tabular}

Linearized standard errors in parentheses. ${ }^{* *} p<0.05, * p<0.10$

Source: Swiss Household panel, first wave in the SHP_I sample (1999).

Notes: Coefficient estimates, data are weighted. Dependent variable: attitudes towards equal opportunity for foreigners; the label 'compulsory education' captures primary and lower secondary education.

Table 13: Ordered probit model: Adding unemployment risk in equation (3)

\begin{tabular}{lllll}
\hline & & \multicolumn{3}{c}{ Occupation level } \\
\cline { 3 - 4 } Sample & All & $\tilde{L_{0}} \& \tilde{L_{1}}$ & $\tilde{L}_{2}$ & $\tilde{L}_{3}$ \\
\hline$\tilde{L_{2}}$ : medium skills (base) & & & \\
$\tilde{L_{0}}$ : missing & -0.006 & & \\
& $(0.110)$ & & \\
$\tilde{L_{1}}$ : Low skills & -0.007 & \\
& $(0.079)$ \\
$\tilde{L_{3}}$ : High skills & $0.455^{* *}$ \\
& $(0.037)$
\end{tabular}




\begin{tabular}{lllll} 
U: Unemployment risk & -0.010 & -0.001 & -0.008 & $-0.035^{* *}$ \\
& $(0.007)$ & $(0.028)$ & $(0.010)$ & $(0.010)$ \\
Control variables & Yes & Yes & Yes & Yes \\
Canton dummies & Yes & Yes & Yes & Yes \\
Proxies for values and beliefs & No & No & No & No \\
\hline Observations & 4,090 & 305 & 1,651 & 2,134 \\
Percentage correctly predicted & $34.1 \%$ & $35.4 \%$ & $28.4 \%$ & $38.2 \%$ \\
\hline
\end{tabular}

Test for joint significance of the excluded instruments in the first stage

\begin{tabular}{|c|c|}
\hline$\succ F$ statistic & $46.0 * *$ \\
\hline
\end{tabular}

Test for exogeneity of $U_{i}$

\begin{tabular}{lrrrr}
$>t$ statistic & -1.59 & 0.21 & 0.70 & -1.08 \\
\hline Linearized standard errors in parentheses. $* *$ & $p<0.05, * p<0.10$
\end{tabular}

Source: Swiss Household panel, first wave in the SHP_I sample (1999).

Notes: Coefficient estimates, data are weighted. Dependent variable: attitudes towards equal opportunity for foreigners.

Table 14: Testing for endogeneity of values - Ordered probit model: Active in the labour market vs. out of the labour force.

\begin{tabular}{|c|c|c|c|c|c|c|c|c|}
\hline \multirow{3}{*}{\begin{tabular}{l}
\multicolumn{2}{c}{$\begin{array}{c}\text { Dependent } \\
\text { variables }\end{array}$} \\
$S: \quad$ Years of \\
schooling
\end{tabular}} & \multicolumn{4}{|c|}{ Active in the labour market } & \multicolumn{4}{|c|}{ Out of the labour force } \\
\hline & \multicolumn{2}{|c|}{$\begin{array}{c}\text { Trust in human rights } \\
\text { organizations }\end{array}$} & \multicolumn{2}{|c|}{$\begin{array}{l}\text { Attachment to } \\
\text { Swiss traditions }\end{array}$} & \multicolumn{2}{|c|}{$\begin{array}{l}\text { Trust in human } \\
\text { rights } \\
\text { organizations }\end{array}$} & \multicolumn{2}{|c|}{$\begin{array}{l}\text { Attachment to } \\
\text { Swiss traditions }\end{array}$} \\
\hline & $\begin{array}{l}0.045^{* *} \\
(0.006)\end{array}$ & & $\begin{array}{l}- \\
0.093 * \\
(0.007)\end{array}$ & & $\begin{array}{l}0.022 * * \\
(0.011)\end{array}$ & & $\begin{array}{l}- \\
0.058 * \\
(0.011)\end{array}$ & \\
\hline $\begin{array}{l}\tilde{L_{2}}: \text { medium skills } \\
\text { (base) }\end{array}$ & & & & & & & & \\
\hline$\tilde{L_{0}}:$ missing & & $\begin{array}{l}0.147 \\
(0.106)\end{array}$ & & $\begin{array}{l}-0.164 * \\
(0.097)\end{array}$ & & - & & - \\
\hline$\tilde{L_{1}}:$ Low skills & & $\begin{array}{l}0.023 \\
(0.093)\end{array}$ & & $\begin{array}{l}0.058 \\
(0.083)\end{array}$ & & $\begin{array}{l}-0.044 \\
(0.122)\end{array}$ & & $\begin{array}{l}0.209 * \\
(0.115)\end{array}$ \\
\hline$\tilde{L_{3}}$ : High skills & & $\begin{array}{l}0.240 * * \\
(0.035)\end{array}$ & & $\begin{array}{l}- \\
0.411 * * \\
(0.036)\end{array}$ & & $\begin{array}{l}0.114 * * \\
(0.055)\end{array}$ & & $\begin{array}{l}- \\
0.300 * * \\
(0.057)\end{array}$ \\
\hline Control variables & Yes & Yes & Yes & Yes & Yes & Yes & Yes & Yes \\
\hline Canton dummies & Yes & Yes & Yes & Yes & Yes & Yes & Yes & Yes \\
\hline Observations & 4,265 & 4,265 & 4,272 & 4,272 & 1,847 & 1,847 & 1,890 & 1,890 \\
\hline
\end{tabular}

Linearized standard errors in parentheses. ${ }^{* *} p<0.05,{ }^{*} p<0.10$

Source: Swiss Household panel, first wave in the SHP_I sample (1999).

Notes: Coefficient estimates, data are weighted.

Table 15: Ordered probit model: baseline models with education and income

\begin{tabular}{lcc}
\hline Equation & $(1)$ & $(2)$ \\
\hline$S:$ Years of schooling & $0.088^{* *}$ & \\
$L_{2}$ (base) & $(0.008)$ & \\
$L_{1}$ : Compulsory education & & $-0.195^{* *}$ \\
& & $(0.067)$ \\
$L_{3}$ : Tertiary education & & $0.355^{* *}$ \\
& & $(0.046)$ \\
Log of income & 0.035 & $0.048^{* *}$ \\
& $(0.023)$ & $(0.023)$
\end{tabular}

Male (base) 


\begin{tabular}{lcc} 
Female & 0.044 & 0.057 \\
Age & $(0.045)$ & $(0.045)$ \\
& 0.014 & 0.013 \\
$\mathrm{Age}^{2}$ & $(0.011)$ & $(0.011)$ \\
& -0.000 & -0.000 \\
Father: Swiss (base) & $(0.000)$ & $(0.000)$ \\
Father: dual nationality & $0.342^{* *}$ & \\
& $(0.159)$ & $0.343^{* *}$ \\
Father: foreign nationality & $0.230^{* *}$ & $(0.160)$ \\
& $(0.088)$ & $0.242^{* *}$ \\
Father: missing nationality & $0.561^{* *}$ & $(0.087)$ \\
& $(0.214)$ & $0.553^{* *}$ \\
Mother: Swiss (base) & & $(0.210)$ \\
Mother: dual nationality & 0.090 & 0.094 \\
& $(0.094)$ & $(0.094)$ \\
Mother: foreign nationality & $0.170^{*}$ & $0.184^{* *}$ \\
& $(0.088)$ & $(0.088)$ \\
Mother: missing nationality & -0.107 & -0.126 \\
& $(0.210)$ & $(0.208)$ \\
Canton dummies & Yes & Yes \\
\hline Observations & 3,101 & 3,101 \\
Percentage correctly predicted & $34.54 \%$ & $34.96 \%$ \\
\hline
\end{tabular}

Linearized standard errors in parentheses. $* * p<0.05, * p<0.10$

Source: Swiss Household panel, first wave in the SHP_I sample (1999).

Notes: Coefficient estimates, data are weighted. Dependent variable: attitudes towards equal opportunity for foreigners; the label 'compulsory education' captures primary and lower secondary education.

Table 16: Ordered probit model: Adding individual values and beliefs

\begin{tabular}{|c|c|c|c|c|c|c|}
\hline \multirow[b]{2}{*}{ Equation } & \multicolumn{3}{|c|}{$\begin{array}{c}\text { No proxies for values and } \\
\text { beliefs }\end{array}$} & \multicolumn{3}{|c|}{ Proxies for values and beliefs } \\
\hline & $(1)$ & (2) & (3) & (1) & $(2)$ & (3) \\
\hline$S:$ Years of schooling & $\begin{array}{l}0.088^{* *} \\
(0.008)\end{array}$ & & & $\begin{array}{l}0.059^{* *} \\
(0.008)\end{array}$ & & \\
\hline$L_{2}$ (base) & & & & & & \\
\hline$L_{1}:$ Compulsory education & & $\begin{array}{l}-0.195^{* *} \\
(0.067)\end{array}$ & & & $\begin{array}{l}-0.081 \\
(0.069)\end{array}$ & \\
\hline$L_{3}:$ Tertiary education & & $\begin{array}{l}0.355^{* *} \\
(0.046)\end{array}$ & & & $\begin{array}{l}0.239^{* *} \\
(0.047)\end{array}$ & \\
\hline$\tilde{L_{2}}:$ Medium skills (base) & & & & & & \\
\hline$\tilde{L_{0}}:$ missing & & & $\begin{array}{c}0.086 \\
(0.136)\end{array}$ & & & $\begin{array}{c}0.014 \\
(0.142)\end{array}$ \\
\hline$\tilde{L_{l}}:$ Low skills & & & $\begin{array}{l}-0.044 \\
(0.096)\end{array}$ & & & $\begin{array}{l}-0.022 \\
(0.100)\end{array}$ \\
\hline$\tilde{L_{3}}$ : High skills & & & $\begin{array}{l}0.471^{* *} \\
(0.043)\end{array}$ & & & $\begin{array}{l}0.320^{* *} \\
(0.045)\end{array}$ \\
\hline Log of income & $\begin{array}{c}0.035 \\
(0.023)\end{array}$ & $\begin{array}{l}0.048^{* *} \\
(0.023)\end{array}$ & $\begin{array}{c}0.034 \\
(0.024)\end{array}$ & $\begin{array}{c}0.029 \\
(0.023)\end{array}$ & $\begin{array}{l}0.040^{*} \\
(0.023)\end{array}$ & $\begin{array}{c}0.027 \\
(0.024)\end{array}$ \\
\hline Proxies for values and beliefs & No & No & No & Yes & Yes & Yes \\
\hline Control variables & Yes & Yes & Yes & Yes & Yes & Yes \\
\hline Canton dummies & Yes & Yes & Yes & Yes & Yes & Yes \\
\hline Observations & 3,101 & 3,101 & 3,101 & 3,101 & 3,101 & 3,101 \\
\hline Percentage correctly predicted & $34.54 \%$ & $34.96 \%$ & $35.38 \%$ & $41.89 \%$ & $41.63 \%$ & $41.15 \%$ \\
\hline $\begin{array}{l}\text { Test for joint significance of values and } \\
\text { beliefs } \\
>F(16,3079)\end{array}$ & & & & $26.19 * *$ & $27.39 * *$ & $26.31 * *$ \\
\hline
\end{tabular}

Linearized standard errors in parentheses. ${ }^{* *} p<0.05,{ }^{*} p<0.10$ 
Source: Swiss Household panel, first wave in the SHP_I sample (1999).

Notes: Coefficient estimates, data are weighted. Dependent variable: attitudes towards equal opportunity for foreigners; the label 'compulsory education' captures primary and lower secondary education.

Table 17: Ordered probit model: Adding unemployment risk in equation (2)

\begin{tabular}{|c|c|c|c|c|}
\hline \multirow[b]{2}{*}{ Sample } & \multirow[b]{2}{*}{ All } & \multicolumn{3}{|c|}{ Education level } \\
\hline & & $L_{1}$ & $L_{2}$ & $L_{3}$ \\
\hline \multicolumn{5}{|l|}{$L_{2}$ (base) } \\
\hline$L_{1}$ : Compulsory education & $\begin{array}{c}-0.058 \\
(0.071)\end{array}$ & & & \\
\hline$L_{3}:$ Tertiary education & $\begin{array}{l}0.231^{* *} \\
(0.047)\end{array}$ & & & \\
\hline$U:$ Unemployment risk & $\begin{array}{l}-0.009 \\
(0.008)\end{array}$ & $\begin{array}{c}-0.011 \\
(0.024)\end{array}$ & $\begin{array}{c}0.001 \\
(0.011)\end{array}$ & $\begin{array}{c}-0.041^{* *} \\
(0.019)\end{array}$ \\
\hline Log of income & 0.034 & 0.002 & 0.028 & 0.055 \\
\hline & $(0.024)$ & $(0.069)$ & $(0.029)$ & $(0.052)$ \\
\hline Control variables & Yes & Yes & Yes & Yes \\
\hline Canton dummies & Yes & Yes & Yes & Yes \\
\hline Proxies for values and beliefs & Yes & Yes & Yes & Yes \\
\hline Observations & 3,047 & 354 & 1,797 & 896 \\
\hline Percentage correctly predicted & $41.32 \%$ & $44.63 \%$ & $40.23 \%$ & $47.10 \%$ \\
\hline
\end{tabular}

Linearized standard errors in parentheses. ${ }^{* *} p<0.05, * p<0.10$

Source: Swiss Household panel, first wave in the SHP_I sample (1999).

Notes: Coefficient estimates, data are weighted. Dependent variable: attitudes towards equal opportunity for foreigners; the label 'compulsory education' captures primary and lower secondary education. Estimation results based on specifications in which variables of values and beliefs are not controlled for deliver the same conclusions.

Table 18: Ordered probit model: Adding unemployment risk in equation (3)

\begin{tabular}{lcccc}
\hline & & \multicolumn{3}{c}{ Occupation level } \\
\cline { 3 - 4 } Sample & All & $\tilde{L_{0} \& \tilde{L_{1}}}$ & $\tilde{L_{2}}$ & $\tilde{L}_{3}$ \\
\hline$\tilde{L_{2}}:$ Medium skills (base) & & & & \\
$\tilde{L}_{0}:$ missing & -0.009 & & & \\
& $(0.147)$ & & & \\
$\tilde{L}_{1}:$ Low skills & -0.037 & & & \\
$\tilde{L_{3}}$ : High skills & $(0.101)$ & & & \\
U: Unemployment risk & $0.315^{* *}$ & & & \\
& $(0.045)$ & -0.006 & 0.006 & $(0.012)$ \\
Log of income & -0.009 & $(0.039)$ & $(0.013)$ & 0.048 \\
& $(0.008)$ & -0.008 & -0.008 & $(0.034)$ \\
Control variables & 0.020 & $(0.077)$ & $(0.041)$ & Yes \\
Canton dummies & $(0.024)$ & Yes & Yes & Yes \\
Proxies for values and beliefs & Yes & Yes & Yes & Yes \\
\hline Observations & Yes & Yes & Yes & 1665 \\
Percentage correctly predicted & 3,047 & 217 & 1,165 & $44.56 \%$ \\
\hline
\end{tabular}

Linearized standard errors in parentheses. ${ }^{* *} p<0.05,{ }^{*} p<0.10$

Source: Swiss Household panel, first wave in the SHP_I sample (1999).

Notes: Coefficient estimates, data are weighted. Dependent variable: attitudes towards equal opportunity for foreigners. Estimation results based on specifications in which variables of values and beliefs are not controlled for deliver the same conclusions.

Table 19: Individuals from 2011 retained in the empirical analysis

\begin{tabular}{|c|c|c|}
\hline & \multicolumn{2}{|c|}{ Sample/Year } \\
\hline & \multicolumn{2}{|c|}{ SHP_I \& SHP_II/2011 } \\
\hline Selection criteria & Active in the labour & Out of the labour force \\
\hline
\end{tabular}




\begin{tabular}{|c|c|c|c|c|c|c|}
\hline & $\begin{array}{l}\text { market } \\
\text { Individuals }\end{array}$ & $\%$ & $\begin{array}{l}\text { Total sample } \\
\text { Individuals }\end{array}$ & $\%$ & $\begin{array}{l}65 \& \text { older } \\
\text { Individuals }\end{array}$ & $\%$ \\
\hline Individual interview completed & 5,085 & 100 & 2,376 & 100 & 1,324 & 100 \\
\hline Registered Swiss voters & 4,543 & 89.3 & 1,937 & 81.5 & 1,256 & 94.9 \\
\hline $\begin{array}{l}\text { Valid information on attitudes towards } \\
\text { foreigner }\end{array}$ & 4,453 & 87.6 & 1,882 & 79.2 & 1,220 & 92.1 \\
\hline $\begin{array}{l}\text { Valid information on gross annual } \\
\text { income }\end{array}$ & 4,096 & 80.6 & & & & \\
\hline $\begin{array}{l}\text { Valid information on risk of } \\
\text { unemployment }\end{array}$ & 4,059 & 79.8 & & & & \\
\hline
\end{tabular}

Source: Swiss Household Panel 2011, thirteen wave in the SHP_I sample and eighth wave in the SHP_II sample, data are unweighted.

Table 20: Individuals from ESS and WVS data retained in the empirical analysis

\begin{tabular}{l|ll|ll}
\hline \multirow{2}{*}{ Selection criteria } & \multicolumn{4}{|c}{ Survey } \\
\cline { 2 - 5 } & \multicolumn{3}{|c|}{ ESS } & \multicolumn{3}{c}{ WVS } \\
\hline Individual interview completed & Individuals & $\%$ & Individuals & $\%$ \\
Active in the labour market & 2,040 & 100 & 2,453 & 100 \\
Swiss citizen/born and at least 18 years old & 1,317 & 64.6 & 1,516 & 61.8 \\
Valid information on years of schooling & 1,148 & 56.3 & 1,260 & 51.4 \\
Valid information on attitudinal variables & 1,145 & 56.1 & - & - \\
\hline
\end{tabular}

Source: European Social Survey 2002 and World Value Survey 1996-2007, data are unweighted.

Note: The ESS provides information on citizenship, while only the place of birth is available in the WVS.

Table 21: Ordered probit model: baseline models with education and income

\begin{tabular}{|c|c|c|}
\hline Equation & (1) & (2) \\
\hline$S:$ Years of schooling & $\begin{array}{l}0.087^{* *} \\
(0.009)\end{array}$ & \\
\hline \multicolumn{3}{|l|}{$L_{2}$ (base) } \\
\hline$L_{l}:$ Compulsory education & & $\begin{array}{c}-0.257^{* *} \\
(0.080)\end{array}$ \\
\hline$L_{3}:$ Tertiary education & & $\begin{array}{l}0.393^{* *} \\
(0.051)\end{array}$ \\
\hline Log of income & $\begin{array}{c}0.005 \\
(0.027)\end{array}$ & $\begin{array}{c}0.013 \\
(0.027)\end{array}$ \\
\hline \multicolumn{3}{|l|}{ Male (base) } \\
\hline Female & $\begin{array}{c}0.038 \\
(0.049)\end{array}$ & $\begin{array}{c}0.051 \\
(0.049)\end{array}$ \\
\hline Age & 0.005 & 0.003 \\
\hline \multirow{2}{*}{$\mathrm{Age}^{2}$} & $\begin{array}{c}(0.014) \\
-0.000\end{array}$ & $\begin{array}{c}(0.014) \\
-0.000\end{array}$ \\
\hline & $(0.000)$ & $(0.000)$ \\
\hline \multicolumn{3}{|l|}{ Father: Swiss (base) } \\
\hline \multirow[t]{2}{*}{ Father: dual nationality } & 0.229 & 0.246 \\
\hline & $\begin{array}{c}(0.198) \\
0.116\end{array}$ & $\begin{array}{c}(0.195) \\
0.122\end{array}$ \\
\hline Father: foreign nationality & $\begin{array}{l}(0.091) \\
0.702^{* *}\end{array}$ & $\begin{array}{l}(0.091) \\
0.685^{* *}\end{array}$ \\
\hline Father: missing nationality & $(0.302)$ & $(0.300)$ \\
\hline \multicolumn{3}{|l|}{ Mother: Swiss (base) } \\
\hline \multirow[t]{2}{*}{ Mother: dual nationality } & 0.002 & 0.014 \\
\hline & $(0.113)$ & $(0.112)$ \\
\hline \multirow[t]{2}{*}{ Mother: foreign nationality } & 0.055 & 0.066 \\
\hline & $(0.093)$ & $(0.093)$ \\
\hline
\end{tabular}




\begin{tabular}{lcc} 
Mother: missing nationality & -0.363 & -0.355 \\
& $(0.301)$ & $(0.299)$ \\
Canton dummies & Yes & Yes \\
\hline Observations & 4,096 & 4,096 \\
Percentage correctly predicted & $64.45 \%$ & $64.65 \%$ \\
\hline
\end{tabular}

Linearized standard errors in parentheses. $* * p<0.05, * p<0.10$

Source: Swiss Household Panel 2011.

Notes: Coefficient estimates, data are weighted. Dependent variable: attitudes towards equal opportunity for foreigners; the label 'compulsory education' captures primary and lower secondary education.

Table 22: Ordered probit mode: Active in the labour market (baseline models) vs. out of the labour force

\begin{tabular}{|c|c|c|c|c|c|c|}
\hline \multirow[b]{3}{*}{ Equation } & \multirow{2}{*}{\multicolumn{2}{|c|}{ Active in the labour market }} & \multicolumn{4}{|c|}{ Out of the labour force } \\
\hline & & & \multicolumn{2}{|c|}{ Total sample } & \multicolumn{2}{|c|}{65 years and older } \\
\hline & (1) & (2) & (1) & (2) & (1) & (2) \\
\hline \multirow[t]{2}{*}{$S:$ Years of schooling } & $0.088^{* *}$ & & $0.081^{* *}$ & & $0.100^{* *}$ & \\
\hline & $(0.008)$ & & $(0.013)$ & & $(0.017)$ & \\
\hline \multicolumn{7}{|l|}{$L_{2}$ (base) } \\
\hline \multirow[t]{2}{*}{$L_{1}$ : Compulsory education } & & $-0.245^{* *}$ & & $-0.325^{* *}$ & & $-0.462^{* *}$ \\
\hline & & $(0.075)$ & & $(0.081)$ & & $(0.098)$ \\
\hline \multirow[t]{2}{*}{$L_{3}$ : Tertiary education } & & $0.409^{* *}$ & & $0.278^{* *}$ & & $0.272^{* *}$ \\
\hline & & $(0.048)$ & & $(0.085)$ & & $(0.104)$ \\
\hline Control variables & Yes & Yes & Yes & Yes & Yes & Yes \\
\hline Canton dummies & Yes & Yes & Yes & Yes & Yes & Yes \\
\hline Observations & 4,453 & 4,453 & 1,882 & 1,882 & 1,220 & 1,220 \\
\hline Percentage correctly predicted & $63.42 \%$ & $63.58 \%$ & $57.97 \%$ & $58.50 \%$ & $57.13 \%$ & $57.87 \%$ \\
\hline
\end{tabular}

Linearized standard errors in parentheses. ${ }^{* *} p<0.05,{ }^{*} p<0.10$

Source: Swiss Household Panel 2011.

Notes: Coefficient estimates, data are weighted. Dependent variable: attitudes towards equal opportunity for foreigners; the label 'compulsory education' captures primary and lower secondary education. Income is not controlled for in the estimated specifications.

Table 23: Ordered probit model: Adding individual values and beliefs

\begin{tabular}{|c|c|c|c|c|c|c|}
\hline \multirow[b]{2}{*}{ Equation } & \multicolumn{3}{|c|}{$\begin{array}{c}\text { No proxies for values and } \\
\text { beliefs }\end{array}$} & \multicolumn{3}{|c|}{ Proxies for values and beliefs } \\
\hline & $(1)$ & (2) & (3) & (1) & $(2)$ & (3) \\
\hline$S$ : Years of schooling & $\begin{array}{l}0.087^{* *} \\
(0.009)\end{array}$ & & & $\begin{array}{l}0.055^{* *} \\
(0.009)\end{array}$ & & \\
\hline$L_{2}$ (base) & & & & & & \\
\hline$L_{1}$ : Compulsory education & & $\begin{array}{c}-0.257^{* *} \\
(0.080)\end{array}$ & & & $\begin{array}{l}-0.129 \\
(0.083)\end{array}$ & \\
\hline$L_{3}$ : Tertiary education & & $\begin{array}{l}0.393^{* *} \\
(0.051)\end{array}$ & & & $\begin{array}{l}0.243^{* *} \\
(0.054)\end{array}$ & \\
\hline$\tilde{L_{2}}$ : Medium skills (base) & & & & & & \\
\hline$\tilde{L_{0}}$ : missing & & & $\begin{array}{l}0.591^{* *} \\
(0.207)\end{array}$ & & & $\begin{array}{l}0.563^{* *} \\
(0.197)\end{array}$ \\
\hline$\tilde{L_{l}}$ : Low skills & & & $\begin{array}{l}-0.076 \\
(0.121)\end{array}$ & & & $\begin{array}{l}-0.003 \\
(0.119)\end{array}$ \\
\hline$\tilde{L_{3}}:$ High skills & & & $\begin{array}{l}0.500^{* *} \\
(0.050)\end{array}$ & & & $\begin{array}{l}0.329^{* *} \\
(0.053)\end{array}$ \\
\hline Log of income & 0.005 & 0.013 & 0.006 & 0.017 & 0.024 & 0.020 \\
\hline & $(0.027)$ & $(0.027)$ & $(0.027)$ & $(0.028)$ & $(0.028)$ & $(0.028)$ \\
\hline Proxies for values and beliefs & No & No & No & Yes & Yes & Yes \\
\hline Control variables & Yes & Yes & Yes & Yes & Yes & Yes \\
\hline Canton dummies & Yes & Yes & Yes & Yes & Yes & Yes \\
\hline
\end{tabular}




\begin{tabular}{lcccccc}
\hline Observations & 4,096 & 4,096 & 4,096 & 4,096 & 4,096 & 4,096 \\
$\begin{array}{l}\text { Percentage correctly predicted } \\
\begin{array}{l}\text { Test for joint significance of values and } \\
\text { beliefs }\end{array}\end{array}$ & $64.45 \%$ & $64.65 \%$ & $64.77 \%$ & $68.65 \%$ & $68.65 \%$ & $69.26 \%$ \\
$>F(24,4066)$ & & & & & & \\
\hline
\end{tabular}

Linearized standard errors in parentheses. ${ }^{* *} p<0.05,{ }^{*} p<0.10$

Source: Swiss Household Panel 2011.

Notes: Coefficient estimates, data are weighted. Dependent variable: attitudes towards equal opportunity for foreigners; the label 'compulsory education' captures primary and lower secondary education. $\tilde{L_{0}}$ includes individuals in armed forces or in missing occupations. Variables for values and beliefs are general trust in people (a 0-to-10 scale variable that is converted into ten dummies, with the highest value 'most people can be trusted' as the reference category, plus a dummy for missing values) and political position left-right (a 0 -to-10 scale variable that is converted into ten dummies, with the highest value 'right' as the reference category, plus three dummies for individuals who do not want/cannot situate themselves, those without any particular political position, and missing values).

Table 24: Ordered probit model: Adding unemployment risk

\begin{tabular}{|c|c|c|c|c|c|c|}
\hline \multirow[b]{2}{*}{ Sample } & \multicolumn{3}{|c|}{ Education level } & \multicolumn{3}{|c|}{ Occupation level } \\
\hline & $L_{1}$ & $L_{2}$ & $L_{3}$ & $\tilde{L_{0}} \& \tilde{L_{1}}$ & $\tilde{L_{2}}$ & $\tilde{L_{3}}$ \\
\hline$U:$ Unemployment risk & $\begin{array}{c}0.010 \\
(0.027)\end{array}$ & $\begin{array}{l}-0.007 \\
(0.013)\end{array}$ & $\begin{array}{c}-0.045^{* *} \\
(0.018)\end{array}$ & $\begin{array}{l}-0.009 \\
(0.043)\end{array}$ & $\begin{array}{l}-0.003 \\
(0.015)\end{array}$ & $\begin{array}{c}-0.039^{* *} \\
(0.014)\end{array}$ \\
\hline Log of income & $\begin{array}{c}0.096 \\
(0.079)\end{array}$ & $\begin{array}{l}-0.012 \\
(0.036)\end{array}$ & $\begin{array}{c}0.017 \\
(0.051)\end{array}$ & $\begin{array}{c}0.013 \\
(0.101)\end{array}$ & $\begin{array}{c}0.013 \\
(0.044)\end{array}$ & $\begin{array}{l}-0.028 \\
(0.039)\end{array}$ \\
\hline Control variables & Yes & Yes & Yes & Yes & Yes & Yes \\
\hline Canton dummies & Yes & Yes & Yes & Yes & Yes & Yes \\
\hline Proxies for values and beliefs & No & No & No & No & No & No \\
\hline Observations & 415 & 2,006 & 1,638 & 216 & 1,564 & 2,279 \\
\hline Percentage correctly predicted & $62.65 \%$ & $59.67 \%$ & $72.47 \%$ & $61.11 \%$ & $55.31 \%$ & $71.43 \%$ \\
\hline
\end{tabular}

Linearized standard errors in parentheses. $* * p<0.05, * p<0.10$

Source: Swiss Household Panel 2011.

Notes: Coefficient estimates, data are weighted. Dependent variable: attitudes towards equal opportunity for foreigners. $\tilde{L_{0}}$ includes individuals in armed forces or in missing occupations.

Table 25: Ordered probit model: Adding unemployment risk with interactions for 1999

\begin{tabular}{|c|c|c|c|c|}
\hline \multirow[b]{2}{*}{ Equation } & \multicolumn{2}{|c|}{ Education level } & \multicolumn{2}{|c|}{ Occupation level } \\
\hline & without income & with income & without income & with income \\
\hline$L_{2}$ (base) & & & & \\
\hline$L_{1}$ : Compulsory education & $\begin{array}{l}-0.076 \\
(0.067)\end{array}$ & $\begin{array}{l}-0.050 \\
(0.086)\end{array}$ & & \\
\hline$L_{3}:$ Tertiary education & $\begin{array}{l}0.263^{* *} \\
(0.050)\end{array}$ & $\begin{array}{l}0.305^{* *} \\
(0.057)\end{array}$ & & \\
\hline$\tilde{L}_{2}:$ Medium skills (base) & & & & \\
\hline$\tilde{L_{0}}:$ missing & & & $\begin{array}{l}-0.183 \\
(0.132)\end{array}$ & $\begin{array}{l}-0.141 \\
(0.176)\end{array}$ \\
\hline$\tilde{L_{l}}:$ Low skills & & & $\begin{array}{c}0.037 \\
(0.093)\end{array}$ & $\begin{array}{l}-0.011 \\
(0.119)\end{array}$ \\
\hline$\tilde{L_{3}}:$ High skills & & & $\begin{array}{l}0.362^{* *} \\
(0.047)\end{array}$ & $\begin{array}{l}0.388^{* *} \\
(0.056)\end{array}$ \\
\hline$L_{1} \times U$ & $\begin{array}{c}0.009 \\
(0.017)\end{array}$ & $\begin{array}{l}-0.003 \\
(0.022)\end{array}$ & & \\
\hline$L_{2} \times U$ & $\begin{array}{l}-0.003 \\
(0.009)\end{array}$ & $\begin{array}{c}0.002 \\
(0.010)\end{array}$ & & \\
\hline$L_{3} \times U$ & $\begin{array}{c}-0.034^{* *} \\
(0.015)\end{array}$ & $\begin{array}{l}-0.043^{* *} \\
(0.017)\end{array}$ & & \\
\hline$\tilde{L_{0}} \times$ & & & $\begin{array}{l}0.118^{* *} \\
(0.050)\end{array}$ & $\begin{array}{l}0.116^{*} \\
(0.066)\end{array}$ \\
\hline$\tilde{L_{l}} \times U$ & & & $\begin{array}{l}-0.012 \\
(0.031)\end{array}$ & $\begin{array}{l}-0.003 \\
(0.039)\end{array}$ \\
\hline
\end{tabular}




\begin{tabular}{|c|c|c|c|c|c|}
\hline \multirow{2}{*}{\multicolumn{4}{|c|}{$\tilde{L_{2}} \times U$}} & 0.011 & 0.010 \\
\hline & & & & $(0.010)$ & $(0.013)$ \\
\hline \multicolumn{4}{|l|}{$\tilde{L_{3}} \times U$} & $-0.031^{* *}$ & $-0.031^{* *}$ \\
\hline & & & & $(0.010)$ & $(0.011)$ \\
\hline \multirow{2}{*}{\multicolumn{2}{|c|}{ Log of income }} & & 0.034 & & 0.019 \\
\hline & & & $(0.024)$ & & $(0.024)$ \\
\hline Observations & & 4,090 & 3,047 & 4,090 & 3,047 \\
\hline $\begin{array}{l}\text { Percentage } \\
\text { predicted }\end{array}$ & correctly & $40.61 \%$ & $41.25 \%$ & $40.76 \%$ & $41.35 \%$ \\
\hline
\end{tabular}

Source: Swiss Household panel, first wave in the SHP_I sample (1999).

Notes: Coefficient estimates, data are weighted. Dependent variable: attitudes towards equal opportunity for foreigners; the label 'compulsory education' captures primary and lower secondary education. Estimation results based on specifications in which variables of values and beliefs are not controlled for deliver the same conclusions.

Table 26: Ordered probit model: Adding unemployment risk with interactions for 2011

\begin{tabular}{|c|c|c|c|c|}
\hline \multirow[b]{2}{*}{ Equation } & \multicolumn{2}{|c|}{ Education level } & \multicolumn{2}{|c|}{ Occupation level } \\
\hline & without income & with income & without income & with income \\
\hline \multicolumn{5}{|l|}{$L_{2}$ (base) } \\
\hline \multirow[t]{2}{*}{$L_{1}$ : Compulsory education } & -0.111 & -0.141 & & \\
\hline & $(0.100)$ & $(0.107)$ & & \\
\hline \multirow[t]{2}{*}{$L_{3}:$ Tertiary education } & $0.304^{* * *}$ & $0.286^{* *}$ & & \\
\hline & $(0.066)$ & $(0.071)$ & & \\
\hline \multicolumn{5}{|l|}{$\tilde{L_{2}}:$ Medium skills (base) } \\
\hline \multirow[t]{2}{*}{$\tilde{L} 0:$ missing } & & & 0.317 & $0.451^{*}$ \\
\hline & & & $(0.226)$ & $(0.244)$ \\
\hline \multirow{2}{*}{$\tilde{L_{l}}:$ Low skills } & & & 0.005 & -0.056 \\
\hline & & & $(0.133)$ & $(0.147)$ \\
\hline \multirow[t]{2}{*}{$\tilde{L_{3}}:$ High skills } & & & $0.393^{* *}$ & $0.380^{* *}$ \\
\hline & & & $(0.065)$ & $(0.069)$ \\
\hline \multirow[t]{2}{*}{$L_{1} \times U$} & -0.010 & -0.005 & & \\
\hline & $(0.027)$ & $(0.029)$ & & \\
\hline \multirow[t]{2}{*}{$L_{2} \times U$} & -0.010 & -0.010 & & \\
\hline & $(0.013)$ & $(0.014)$ & & \\
\hline \multirow[t]{2}{*}{$L_{3} \times U$} & $-0.034^{*}$ & $-0.033^{*}$ & & \\
\hline & $(0.018)$ & $(0.019)$ & & \\
\hline \multirow[t]{2}{*}{$\tilde{L_{0}} \times U$} & & & 0.108 & 0.101 \\
\hline & & & $(0.092)$ & $(0.106)$ \\
\hline \multirow[t]{2}{*}{$\tilde{L_{l}} \times U$} & & & 0.017 & 0.028 \\
\hline & & & $(0.037)$ & $(0.038)$ \\
\hline \multirow[t]{2}{*}{$\tilde{L_{2}} \times U$} & & & -0.004 & -0.006 \\
\hline & & & $(0.015)$ & $(0.015)$ \\
\hline \multirow[t]{2}{*}{$\tilde{L_{3}} \times U$} & & & $-0.036^{* *}$ & $-0.033^{* *}$ \\
\hline & & & $(0.014)$ & $(0.015)$ \\
\hline \multirow{2}{*}{ Log of income } & & 0.020 & & 0.015 \\
\hline & & $(0.028)$ & & $(0.029)$ \\
\hline Observations & 4,401 & 4,059 & 4,401 & 4,059 \\
\hline $\begin{array}{l}\text { Percentage } \\
\text { predicted }\end{array}$ & $67.92 \%$ & $68.81 \%$ & $68.35 \%$ & $69.50 \%$ \\
\hline
\end{tabular}

Source: Swiss Household Panel 2011.

Notes: Coefficient estimates, data are weighted. Dependent variable: attitudes towards equal opportunity for foreigners; the label 'compulsory education' captures primary and lower secondary education. Estimation results based on specifications in which variables of values and beliefs are not controlled for deliver the same conclusions. 